\title{
EL BARROCO POPULAR DE TEXCOCO
}

\author{
$\mathbf{P} \mathbf{O}$
}

\author{
RAUL FLORES GUERRERO
}

I A arquitectura, quizá más que cualquier otra manifestación del es1 píritu creador del hombre, ha estado siempre matizada por caracteres regionales. $Y$ ello se debe a que la arquitectura, como arte, es el reflejo de las circunstancias ambientales, históricas y sociales del pueblo que la crea, pero, además, antes de que surgiera la tesis contemporánea del supuesto internacionalismo arquitectónico, tesis que arranca de los desacatos estilísticos del Romanticismo - templos griegos sirviendo de iglesias en París y de monumentos conmemorativos en los Estados Unidos; formas góticas adaptadas para los palacetes londinenses o las universidades norteamericanas- existió siempre una integración plástica entre la arquitectura, la escultura y la pintura, acentuándose así, con la coexistencia de las tres artes, el carácter regional de los edificios.

Desde los remotos tiempos de la gran arquitectura helénica las construcciones mostraban rasgos peculiares, según la región en donde se erigían. Baste recordar la diferenciación en el empleo de los órdenes y aún la variante en algunas plantas de los templos de la península griega $y$ otros levantados en las provincias orientales.

Esta diferenciación es tanto más notable en el gótico, estilo que tuvo tantas variantes como países en que se realizó. Existe un gótico francés y uno español, uno alemán y otro inglés, un estilo gótico italiano distinto del belga o del holandés, y aún, dentro de estas distinciones por países, hay variantes estilísticas por regiones y por escuelas escultóricas; sería suficiente con recordar, en Francia, las de Champaña, Anjou, Normandia, 
Borgoña, Poitou, Languedoc y la Isla de Francia principalmente. Y qué decir del Barroco: el místico barroco español y el barroco alemán, el cortesano recocó francés y el apasionado y sensual estilo italiano de Bernini y Borromini.

E1 Barroco americano, de tan original y distinto al peninsular, casi no merece llamarse colonial, y a su vez son diferentes el barroco peruano, el ecuatoriano, el brasileño y, claro está, el mexicano.

Continuando con el deslinde de las características regionales de este estilo se puede apreciar cómo a cada provincia de la antigua Nueva España correspondió un barroco diferente, lo que se explica por la variación en los materiales empleados en cada lugar para la construcción de los edificios y la diversa tradición artística de los pueblos que los erigían, patente, sobre todo, en la habilidad manual de los artistas y artesanos que trabajaban la piedra, la argamasa, el estuco o la madera. Es claro que el barroco del Bajio y el zacatecano, el brillante barroco poblano y el michoacano, el chiapaneco y el de la ciudad de México, por no mencionar sino algunos ejemplos, no obstante estar ligados por un origen común y una voluntad de forma fincada en los mismos principios, son todos ellos distintos. La coloración de la cantera o del barro, el tratamiento de los relieves, el movimiento de las cornisas y molduras, la composición de las fachadas son, todos, elementos que permiten distinguir a qué parte de México corresponde tal o cual construcción, tal o cual retablo. No es pues arbitrario el considerar en este ensayo las características diferenciales de un estilo regional como es el texcocano.

Una vez explicada la lógica de lo regional en el estilo, cabe hacer un somero análisis de su carácter popular. Para ello es necesario aventurarse a definir algo que hasta ahora no ha sido definido y que, durante tantos años, se ha prestado a innumerables confusiones y polémicas.

En primer lugar surge, como problema de dilucidación, el de la naturaleza de la arquitectura popular en general. ¿Cómo es y cuáles son los rasgos distintivos que permiten designarla como tal? $\mathrm{El}$ asunto no deja de ser complejo pero, por eso mismo, interesante.

El número de variantes y la riqueza arquitectónica del barroco mexicano presenta incontables ejemplos, agrupados naturalmente por regiones, de edificios clasificables como obras de arquitectura popular. Este carácter puede encontrarse desde las sencillas construcciones indígenas hechas con materiales deleznables, como la palma, el carrizo, el adobe y el zacate, hasta edificios tan importantes como es el templo de Santo Domingo en San Cristóbal las Casas. Entre estos dos extremos se 
halla una gran cantidad de edificios -casas provincianas, capillas, haciendas- de tipo popular, erigidos en pueblos y ciudades de México.

Entre las características de popularismo en la arquitectura resalta, en primer término, el anonimato. Una obra de arte popular, cualquiera que esta sea, es siempre anónima. $Y$ es natural, puesto que el artista, al hacerla, no pretende ninguna celebridad, ninguna trascendencia. Crea respondiendo, por una parte, a las necesidades de la comunidad y por otra a un espontáneo -e indudablemente momentáneo- placer por el color y el volumen, a un gusto, personal casi siempre, por las formas que nacen de su intuición y de su imaginación para ser realizadas por sus manos o bien bajo su voluntad rectora. No existe, en el artista popular, la conciencia, clara y precisa, de estar creando una "obra de arte". De ahí que la arquitectura popular sea eminentemente caprichosa. De ahí también el trastocamiento de todo orden, la reversión de lo establecido en el arte culto, la ruptura de toda regla que pueda limitar su absoluta libertad creativa. En el caso de la arquitectura popular existen por lo general influencias de edificios cercanos realizados por arquitectos preparados; sólo que el arquitecto popular y los escultores que trabajan a sus órdenes toman de ellos los elementos según su arbitrio, siguiendo sus afinidades emocionales y estéticas con tal o cual forma, con tal o cual motivo ornamental. A veces les gusta tanto que lo hacen destacar de un modo desmesurado, sin importarles, o más bien sin tener siquiera idea, de que en el edificio inspirador esa forma o motivo está sometida a un concepto de orden y armonía establecido por determinados cánones estilísticos. Es por eso frecuente encontrar columnas insignificantes soportando un capitel majestuoso y exuberante; plásticamente es, éste último, lo fundamental para el artista popular; el fuste lo coloca allí en un plano estético secundario y sólo porque no puede dejar de emplearlo como sustentante indispensable del capitel. Otras veces, los remates que en las iglesias principales, las inspiradoras, apenas se destacan en lo más alto de la fachada o sobre alguna balaustrada, en los templos populares adquieren una importancia notable, una vida arquitectónica propia e independiente.

Es bastante común el considerar popular a lo mal hecho, a lo deforme. Sin embargo tal consideración parte del hecho de juzgar al arte popular según los valores del arte culto. Como en todo arte, en el popular existe buen arte y mal arte, o por mejor decir existen obras de arte y otras que no lo son; $y$ si bien es cierto que el criterio para justipreciar su valor no puede estar regido por ningunos lineamientos, puesto que el 
DOI: http://dx.doi.org/10.22201/iie.18703062e.1956.24.604

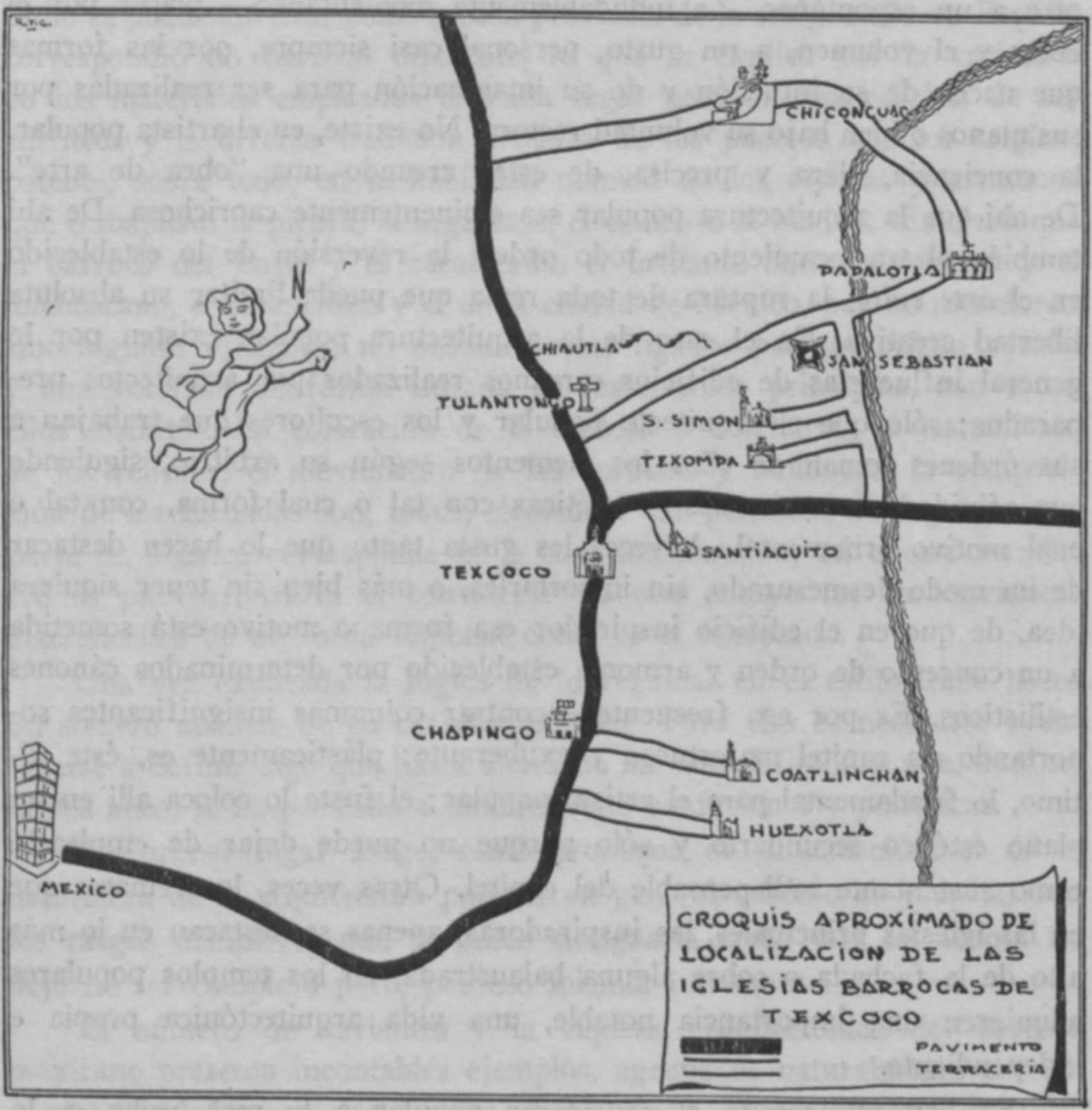


arte popular mismo está sujeto siempre a constantes cambios y contrastes sorpresivos, existen sin embargo, en las obras de arte de este tipo, ciertos valores propios, distintos por completo a los del arte culto (una armonía de la desproporción, que para el pueblo y el artista popular es una armonía de proporciones distintas) que permiten al espectador sentir, más bien que analizar, cuando una creación de arquitectura popular está dentro de los límites de la estética y cuando los ha transgredido para dejar de ser obra de arte.

Al tratar de la arquitectura barroca popular de Texcoco se considerará aquí, al mismo tiempo, la escultura (tanto la llamada de bulto como el relieve) ya que ambas están de tal manera ligadas -integradasque deslindar una de otra sería romper con el orden en que se presentan y por lo tanto considerar sólo un aspecto de esa unidad que constituye cada edificio.

En algunas iglesias surge, claro está, un problema: el de que, perteneciendo la decoración al ámbito de lo popular, la estructura del edificio y la composición de la fachada demuestran la intervención de una mente arquitectónica preparada y conocedora. Tal es el caso de los templos de Huexotla y Coatlinchan, de Chiautla y de San Sebastián. Considero que estos edificios, debido a su importancia artística, no pueden ser pasados por alto en este estudio, aunque por su falta de "pureza" popular serán tratados con menos detenimiento.

La escultura, sobre todo bajo la forma de relieve, es la nota más popular de la arquitectura texcocana. Se trata de un relieve de calidades inconfundiblemente indígenas, trabajado en un solo plano en la mayoría de los casos, sin salientes ni entrantes bruscas, como si sus líneas gruesas estuviesen grabadas en el paño del aplanado con un buril gigantesco; este tratamiento les comunica a las formas un gusto peculiar; tal vez gracias a él se siente una enorme sencillez y espontaneidad en la factura, se adivina - tantos siglos después- el placer sensual del artista al modelar esas formas perfectamente diferenciadas, aprendidas por los autores anónimos en el diario contacto, visual y sensorial, con la naturaleza; formas queridas por su cercanía que fueron plasmadas en el estuco, en el barro o en la piedra con el afán de hacerlas vivir a través de los años; formas concisas que de un solo golpe de vista producen la imagen concreta del objeto que representan: sin ningún detallismo inútil, con una economía de líneas que no puede sino recordar las obras maestras 
de la escultura azteca en la que una rana, un tigre o una serpiente eran realizados monolíticamente con todas sus caracteristicas, de la manera más sintética y esencial: ni una sola línea más se necesitaba para representar al animal pero tampoco una sola podía faltar, so pena de que dejaran inmediatamente de ser la fiel representación artística de la rana, el tigre o la serpiente.

Este esencialismo formal, que la cultura europea redescubrió hasta el siglo $\mathrm{xx}$, fué heredado por los artistas populares de la época barroca, de sus ancestros prehispánicos y hasta la fecha continúan practicándolo en su cerámica, en sus textiles, en su arquitectura. Sin embargo siendo estas formas esenciales y sintéticas en lo particular, es decir cada forma en sí, al reunirse constituyen conjuntos decorativos que por su complicación y abigarramiento parecen confusos, pero aún así producen una sensación de armonía, de equilibrio, que se debe a un sentido intuitivo de la composición artística, a la gran habilidad manual y a la notable sensibilidad plástica de sus ignorados creadores.

La arquitectura popular de Texcoco es en todos sus ejemplos estilísticamente barroca y por lo tanto fué hecha durante los siglos xvir y xvirr. No podía ser de otra manera tratándose de una manifestación del espíritu del pueblo mexicano cuya afinidad con el claroscuro, el dinamismo y la complejidad formal de esta modalidad artística es uno de los factores determinantes para que el barroco mexicano merezca un sitio notable e indiscutible en el panorama histórico mundial de este estilo; afinidad que sobrevive tradicionalmente hasta los tiempos actuales en que las obras menores de arte popular pueden fácilmente considerarse barrocas.

El estudio detallado de las iglesias populares de Texcoco merece todo un libro, de ahí que en este ensayo recurra simplemente a esbozar las características generales de su peculiar estilo a partir del estudio de los elementos arquitectónicos más representativos.

\section{Los arcos atriales}

$\mathrm{El}$ acceso a los atrios de las iglesias texcocanas se realiza generalmente por tres arcadas, una frontal y dos laterales.* Cada una de estas

* Hay alguna que otra variante en esta disposición, tal es el caso de San Juan Texompan en donde además de la entrada frontal aparece una arcada al lado de la iglesia. 


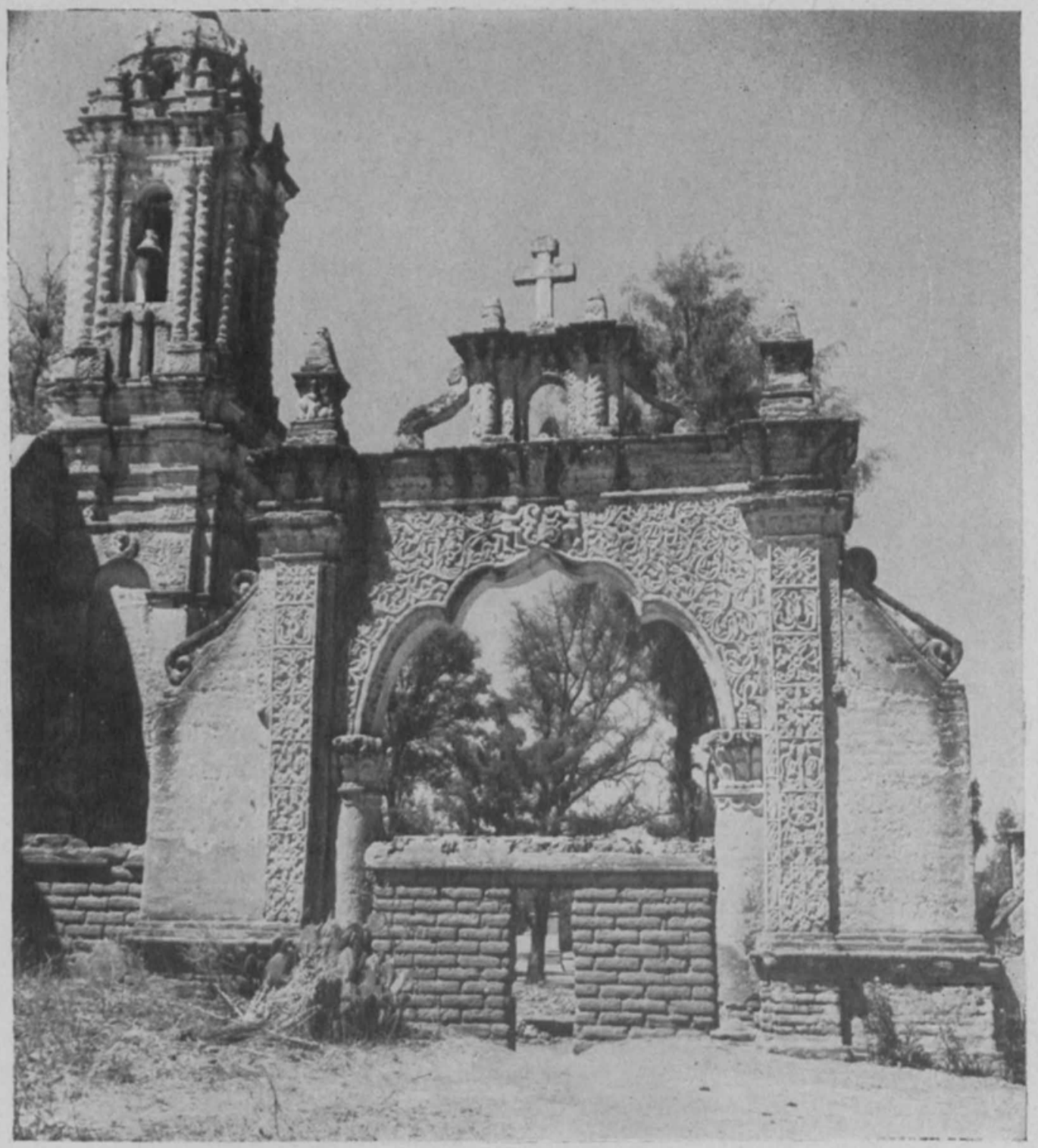

1. Arco en el atrio de San Juan Texompa. (Fotos de Raúl Flores Guerrero.) 
DOI: http://dx.doi.org/10.22201/iie.18703062e.1956.24.604

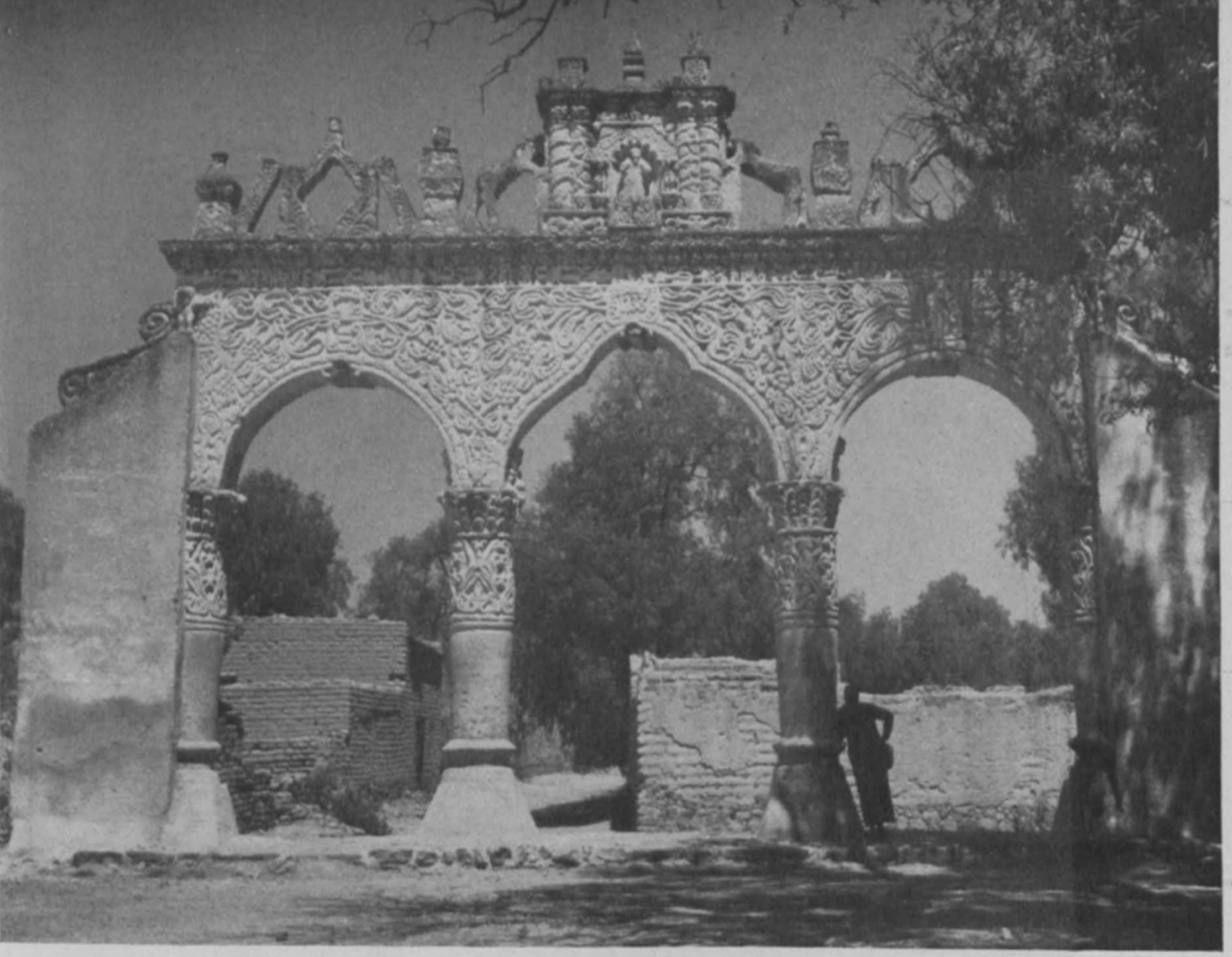

2. Arco atrial de Papalotla.

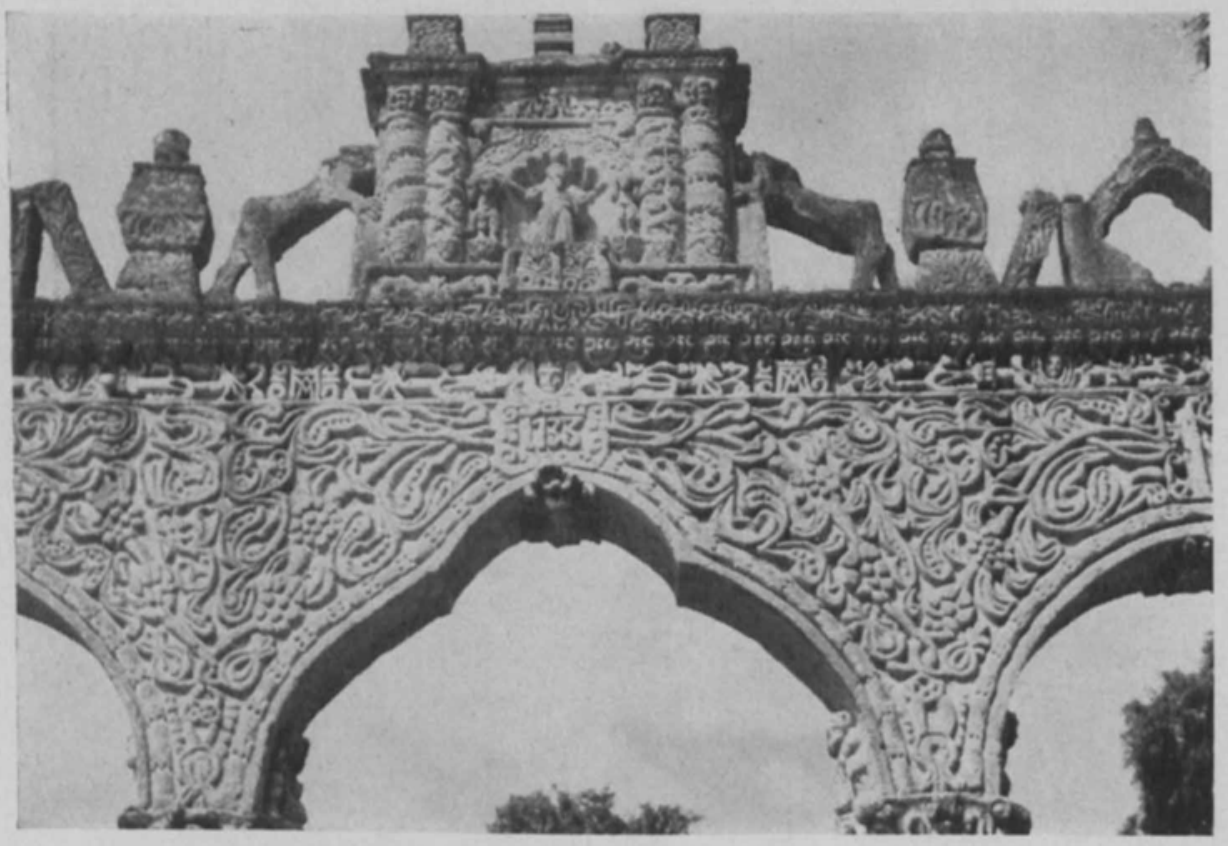

3. Arco atrial de Papalotla. Detalle. 


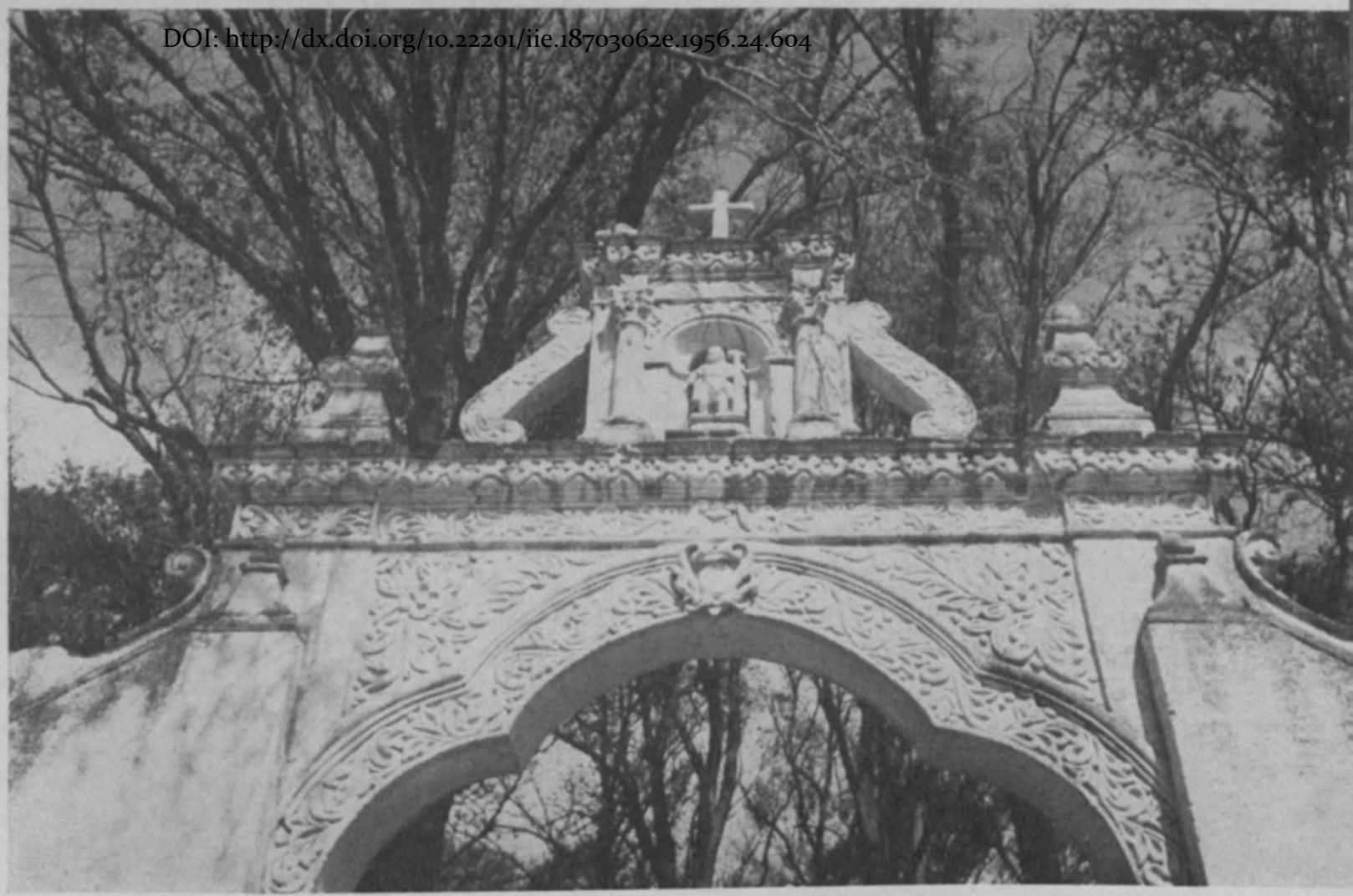

4. Arco de Santa María Tulantongo.

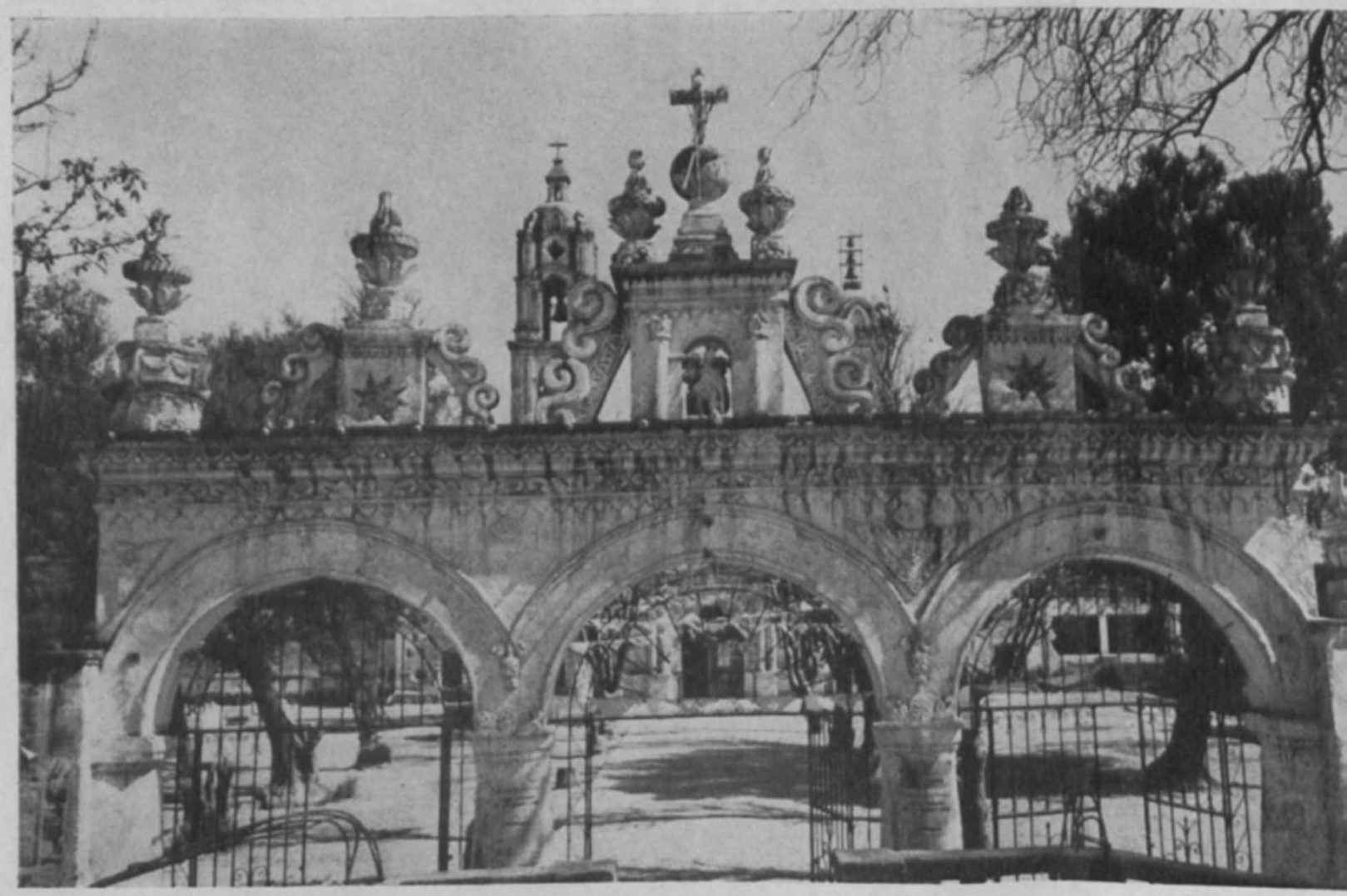

5. Arcada en el atrio de San Miguel Chiconcuac. 


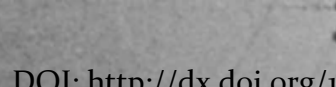

/10.22201/iie.18703062e.1956.24.60

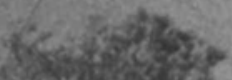

(6)

Wh

졸

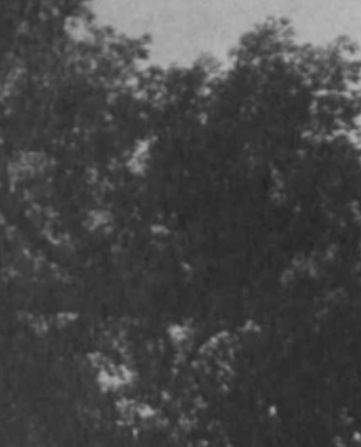

$$
\text { s.e }
$$$$
-x^{2}+x^{2}
$$

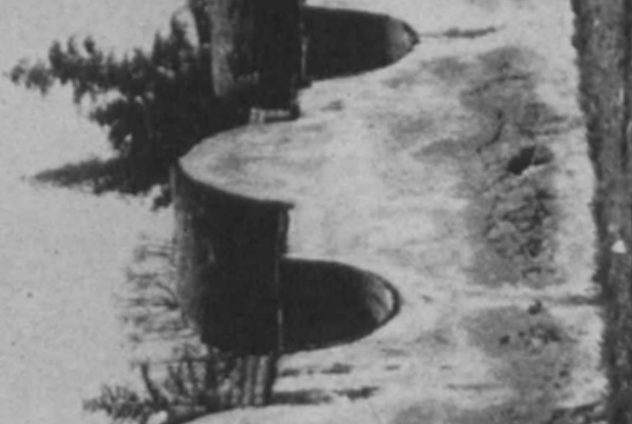




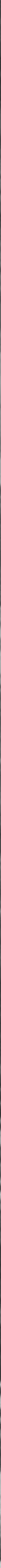

7. Barda en el atrio de la iglesia de San Miguel Chiconcuac. 


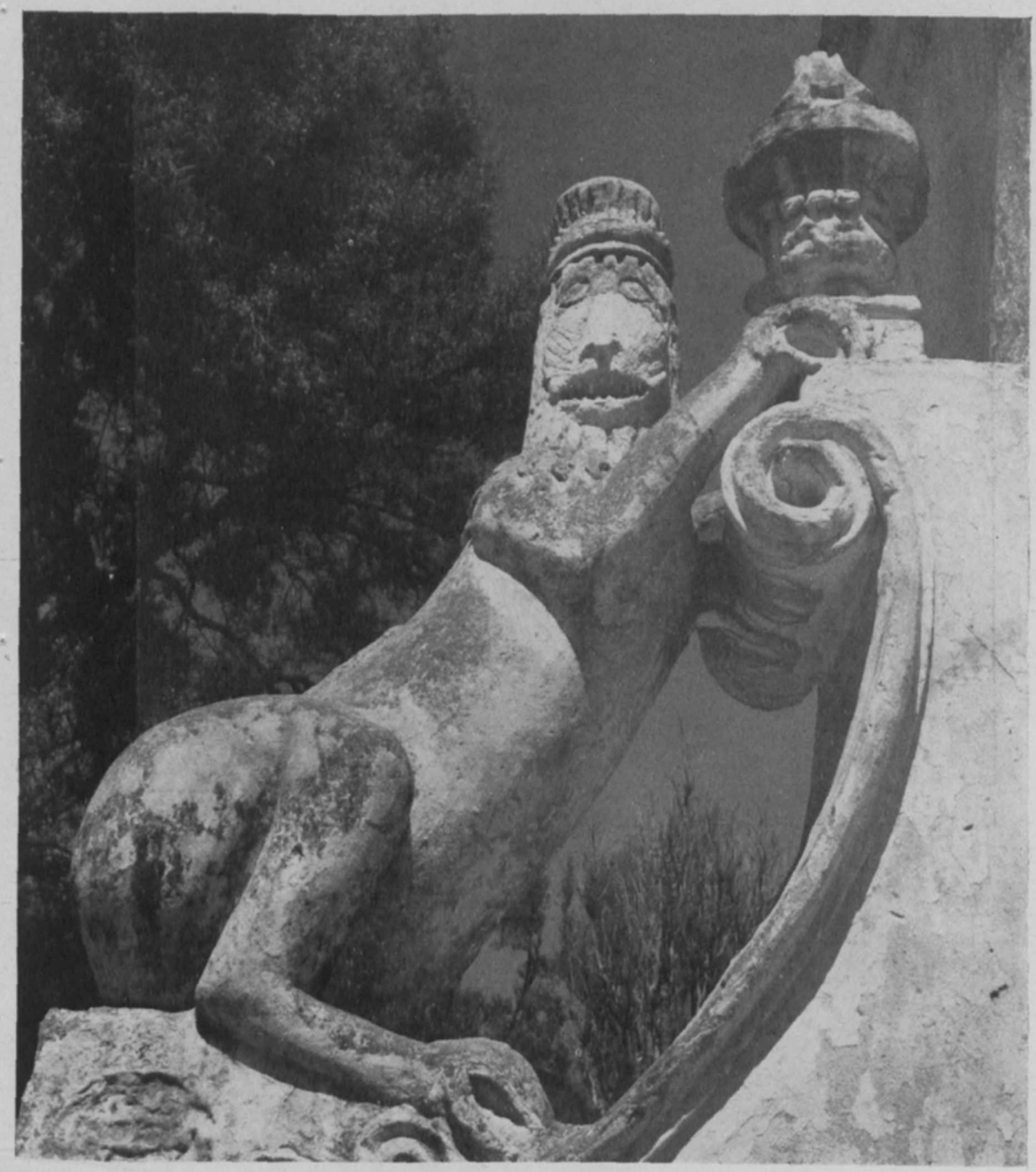

10. Escultura en la barda atrial de Chiconcuac. 
DOI: http://dx.doi.org/10.22201/iie.18703062e.1956.24.604

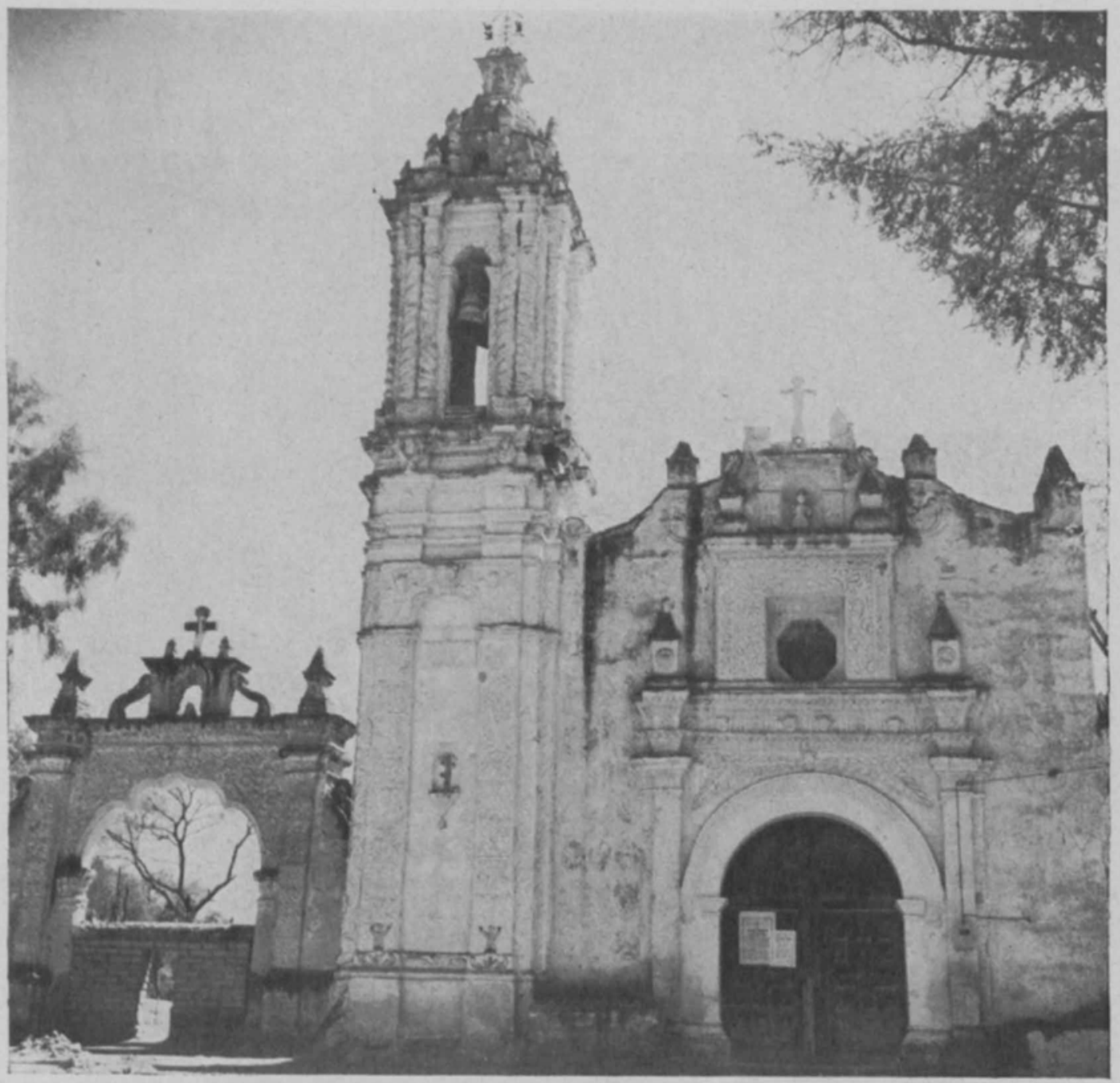

11. Fachada y arco atrial de San Juan Texompa. 
Ag

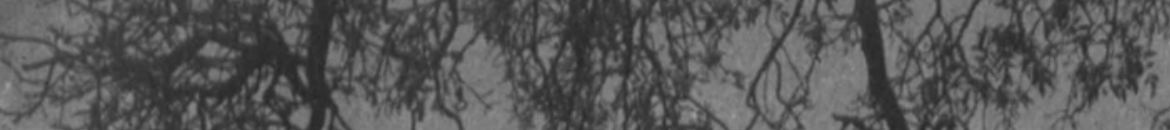

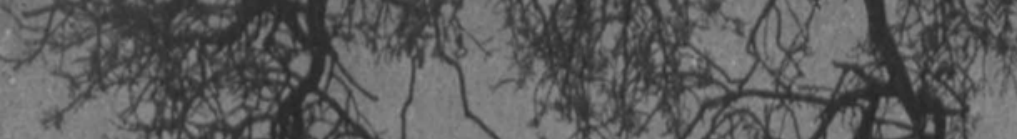
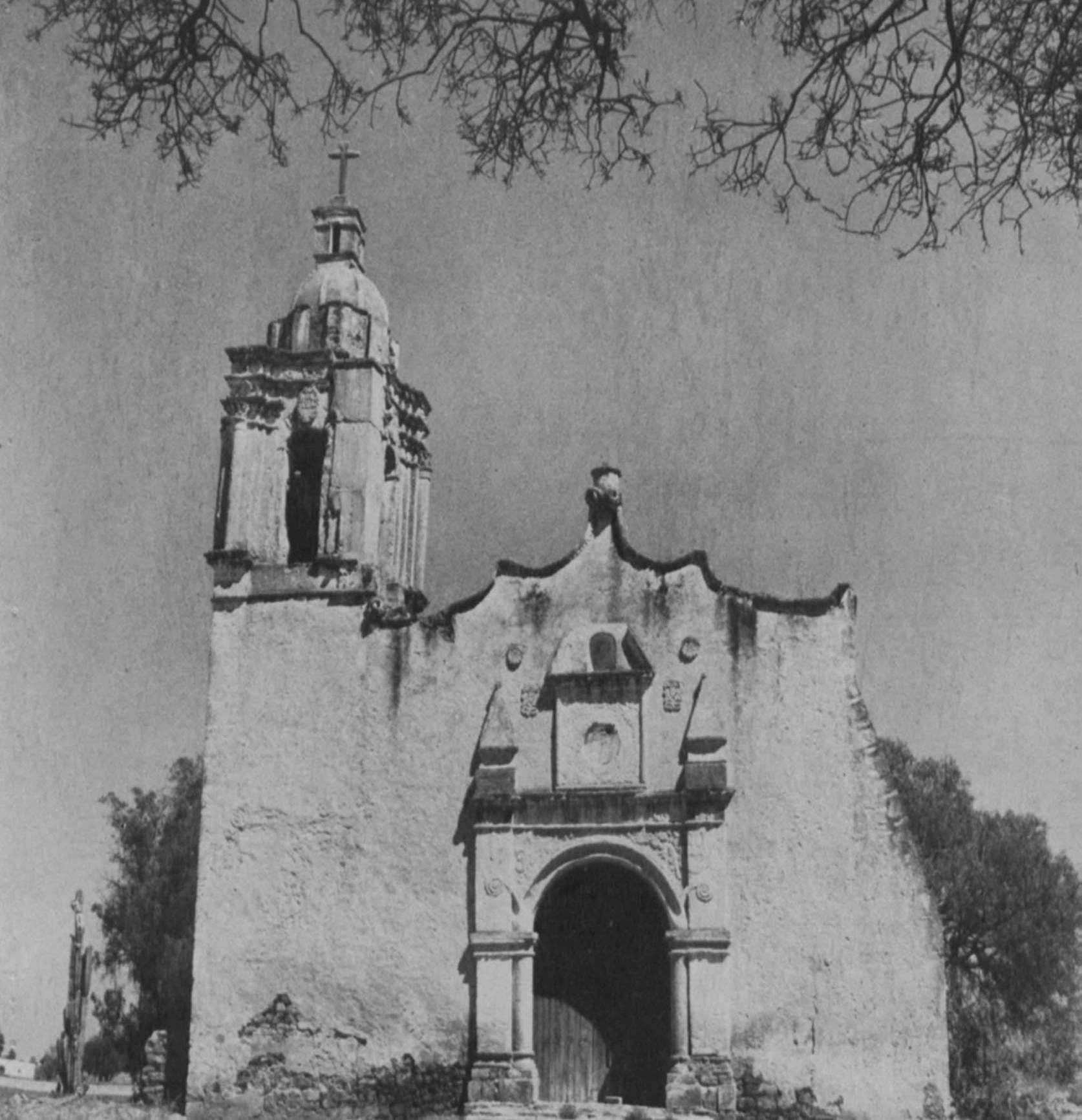


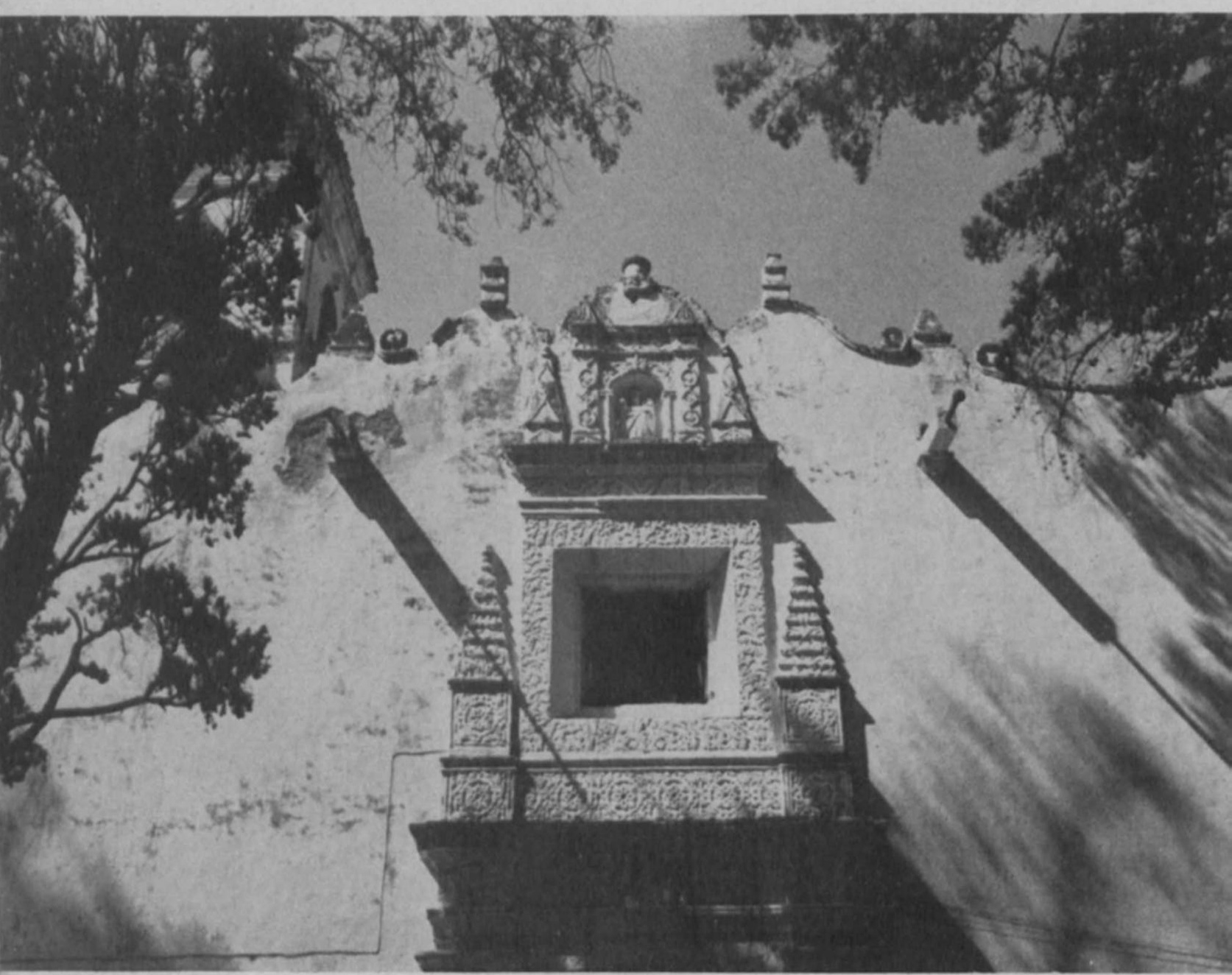

13. Ventana de la iglesia de Santa Maria Tulantongo. 
DOI: http://dx.doi.org/10 22201/iie.18703062e.1956.24.604 vithent

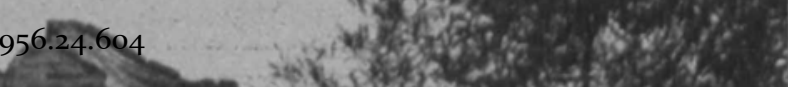

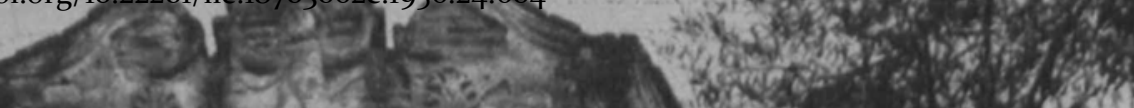
I.

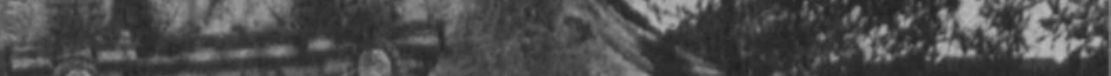

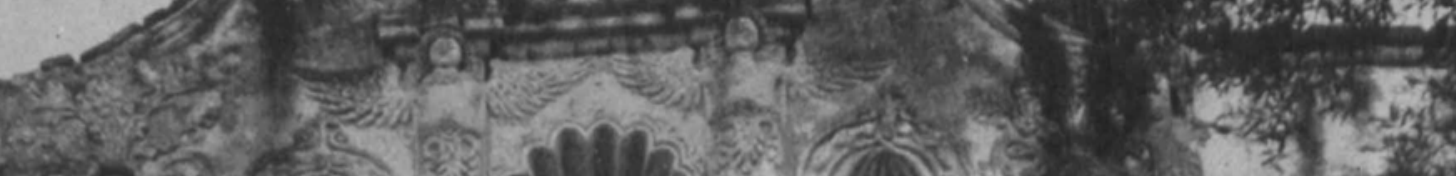

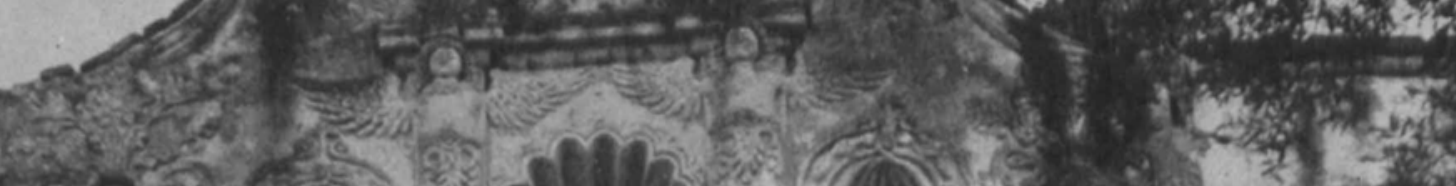

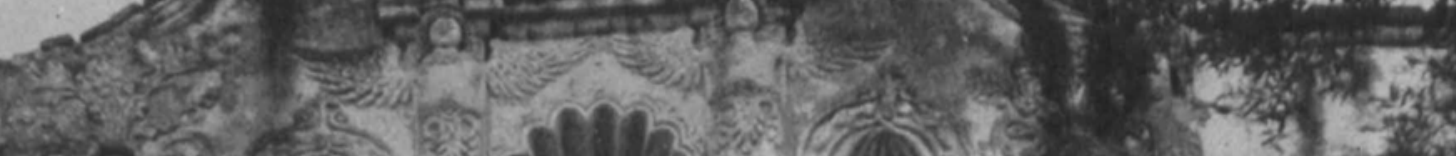

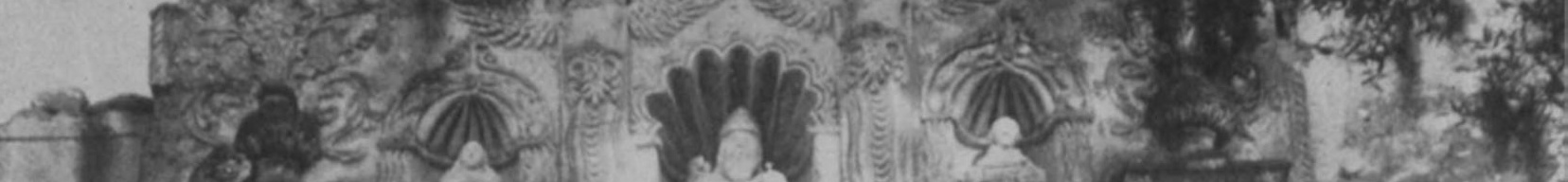
(3) (4) f. sicy

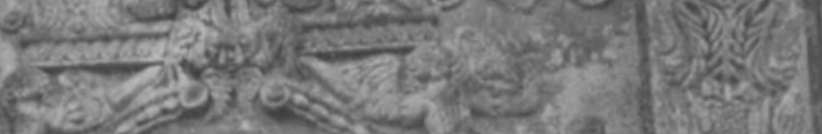

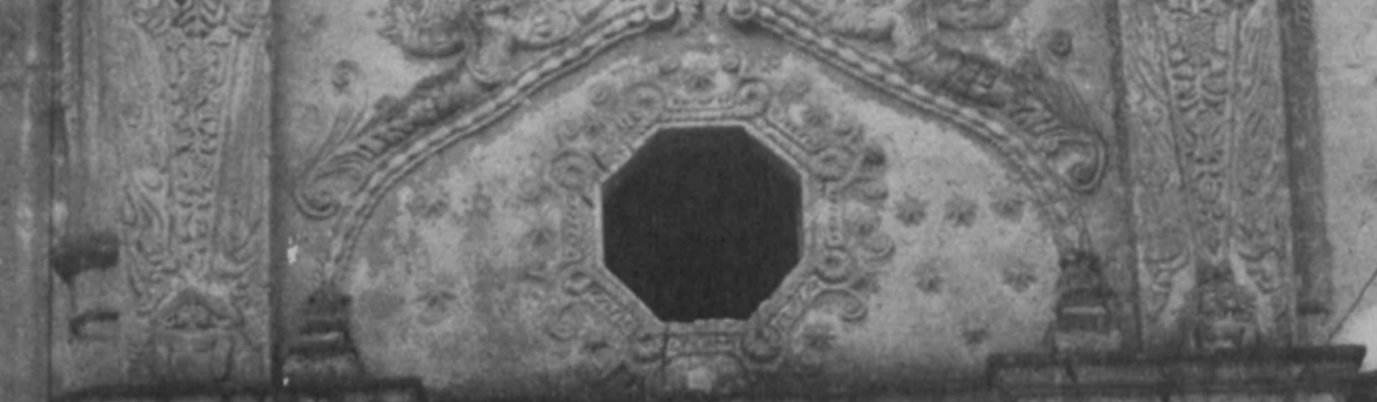

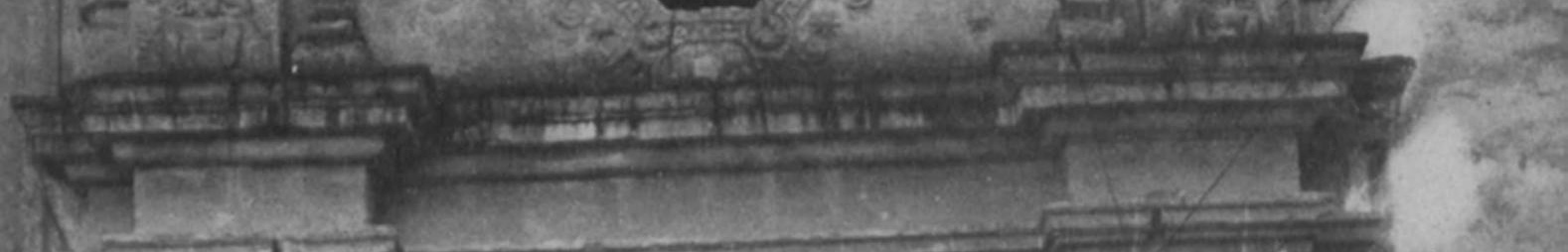

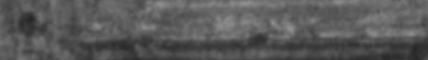

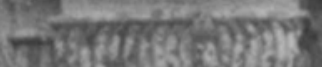
(1)

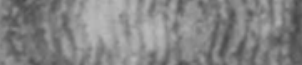

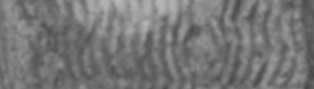

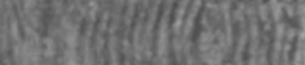

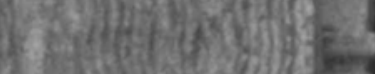

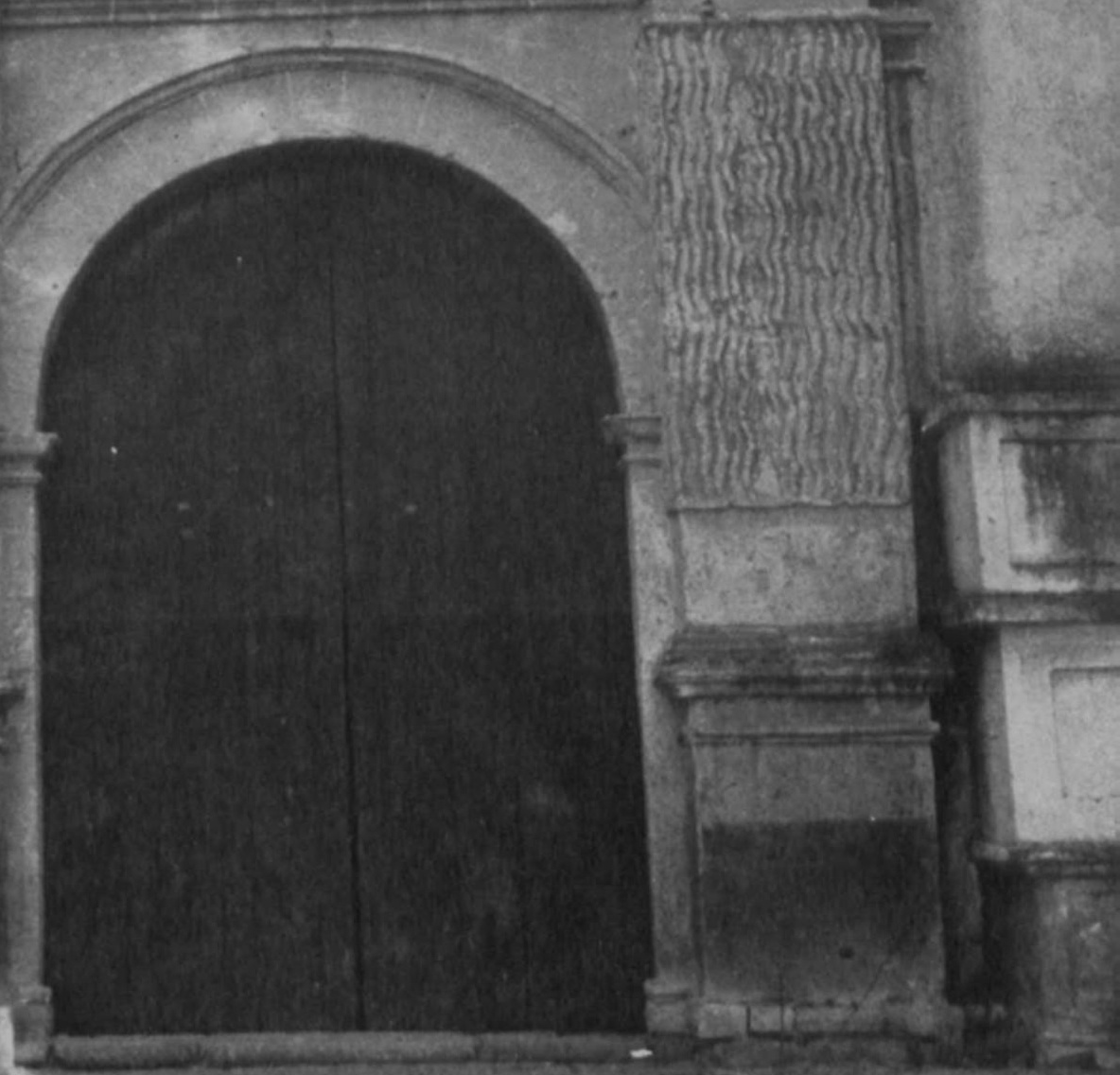


16. Fachada de San Simón. Detalle.

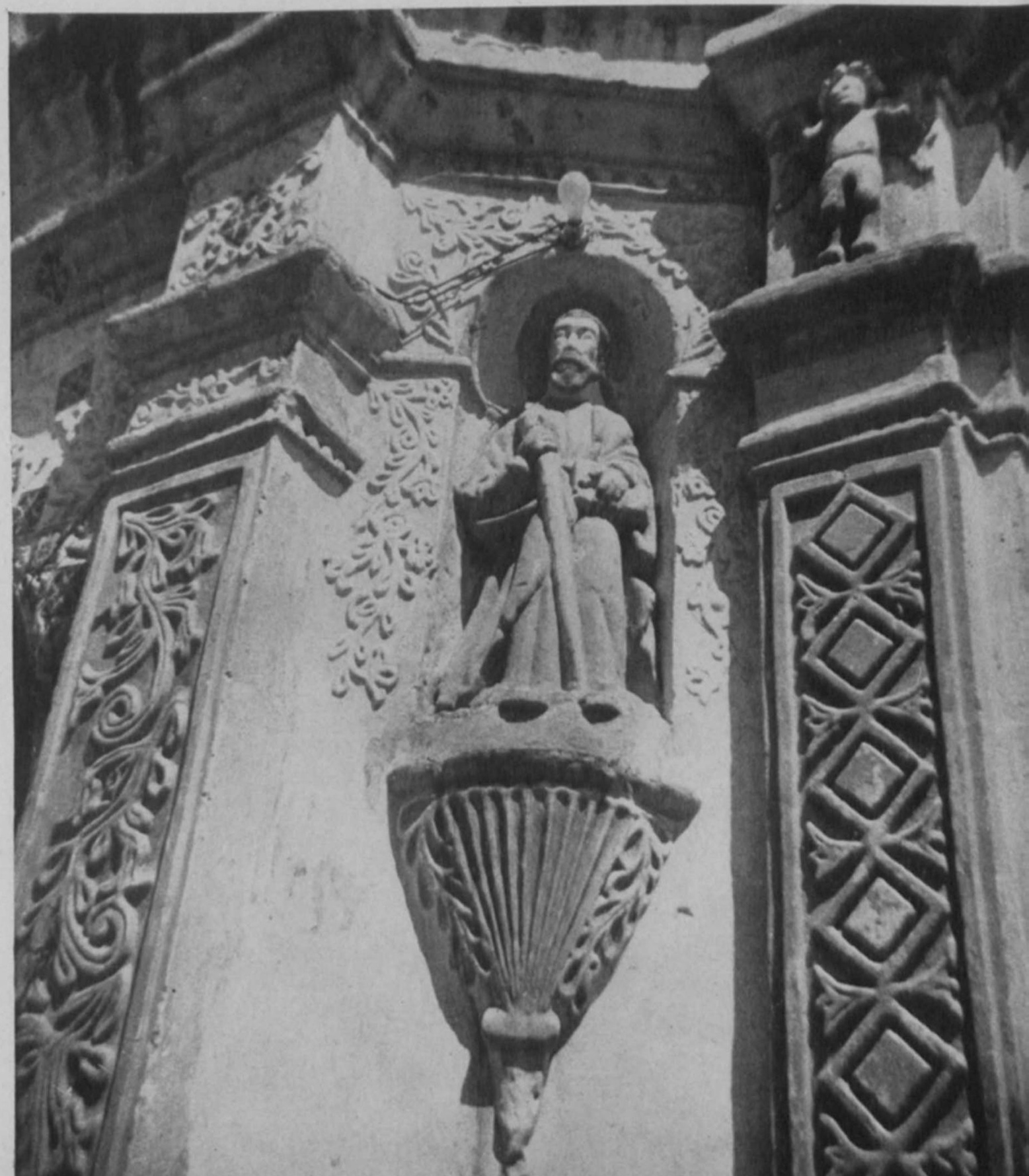




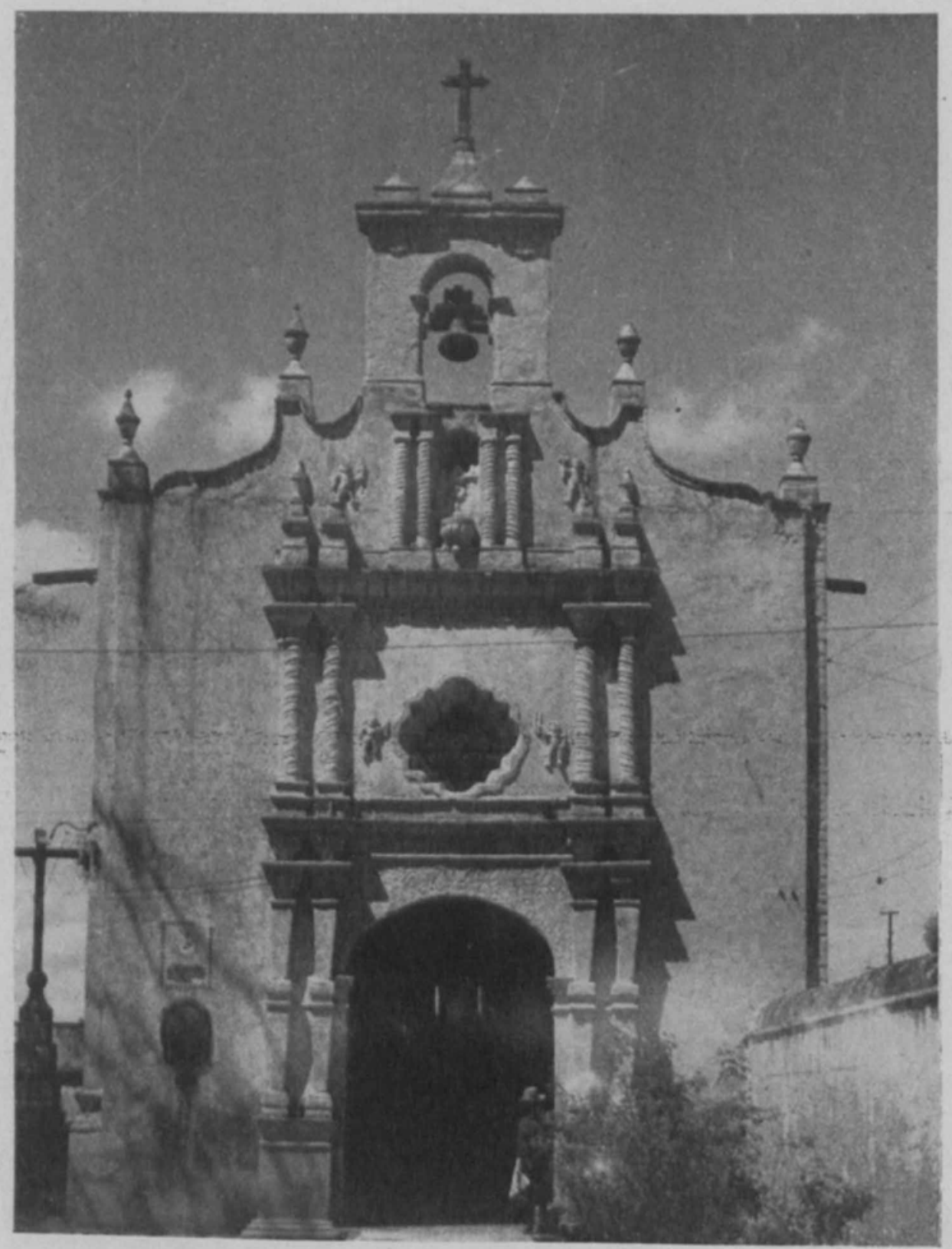

17. Capilla de San Felipe, en el atrio de San Francisco de Texcoco. 


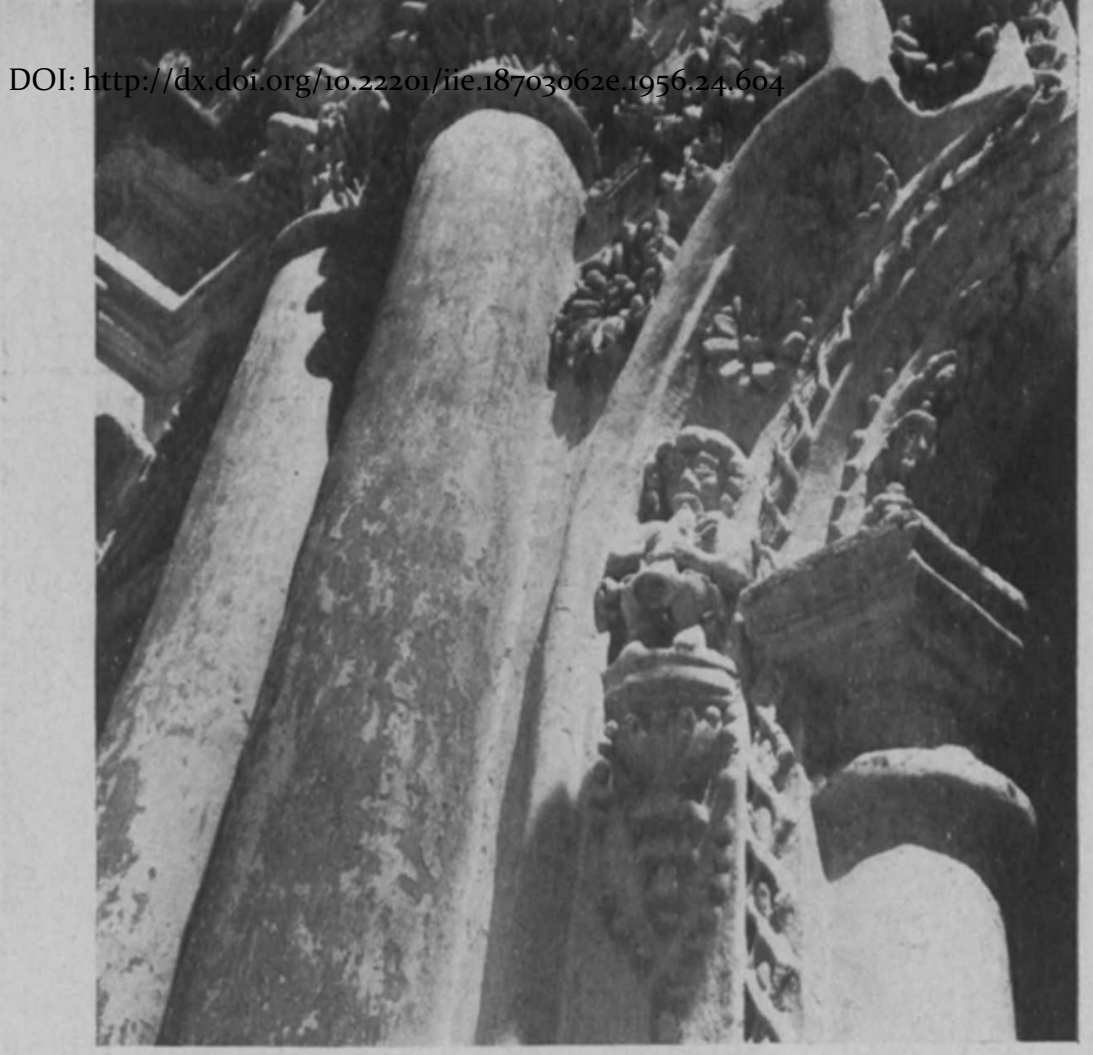

20. Fachada de la iglesia de Chiconcuac. Detalle.

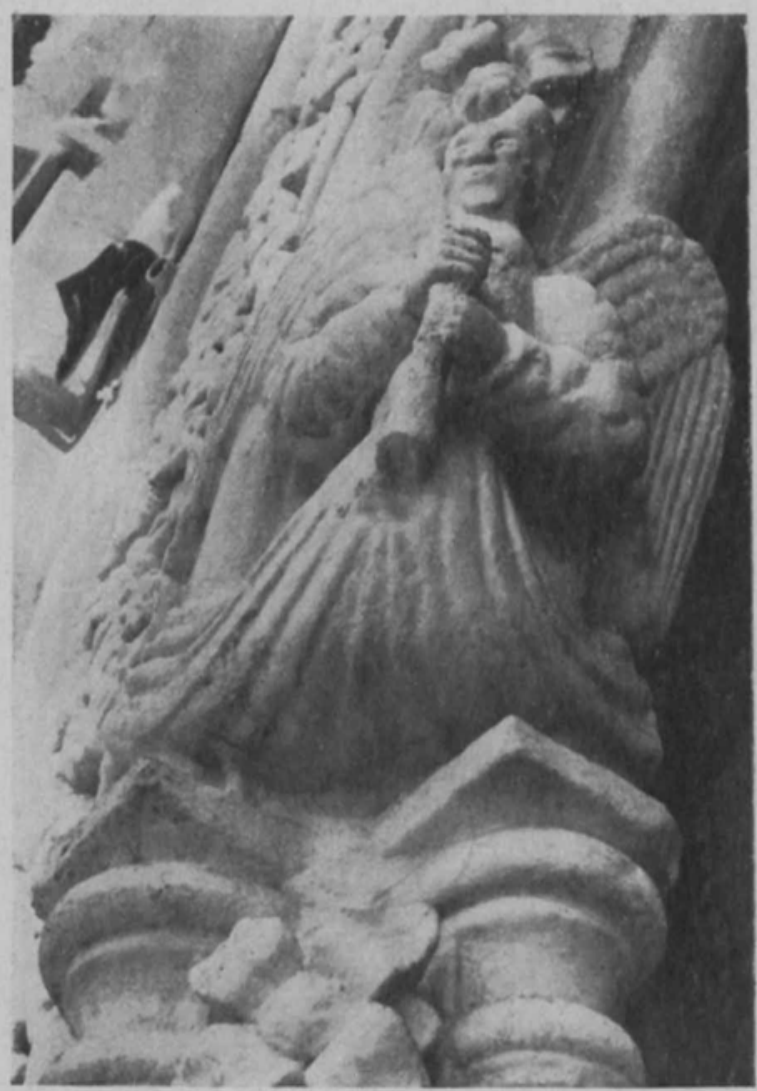

21. Detalle de la portada de "La Conchita" en Texcoco (Siglo XvI). 
DOI: http://dx.doi.org/10.22201/iie.18703062e.1956.24.604

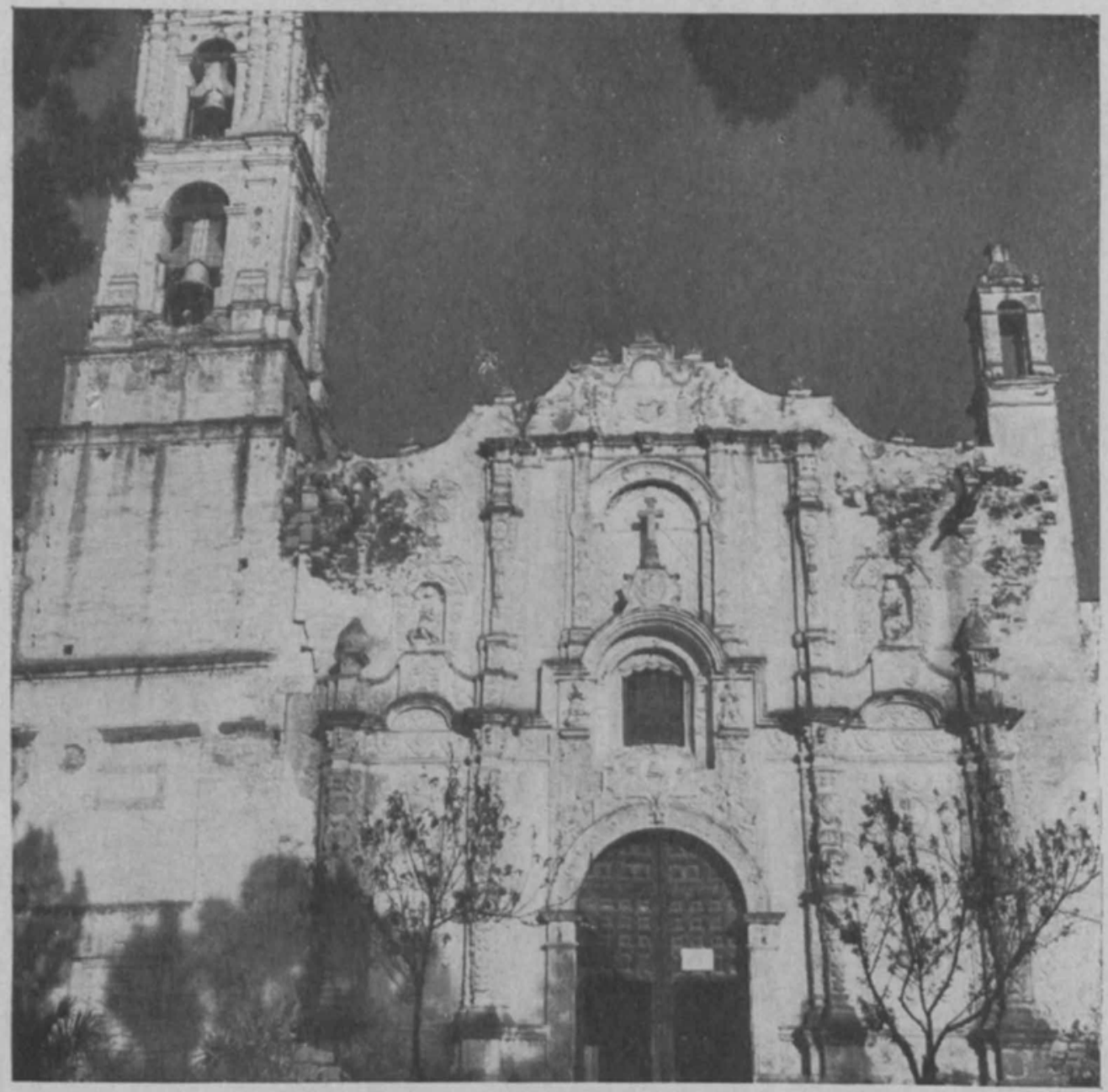

22. Fachada de la iglesia de Huexotla.

23. Detalle. 


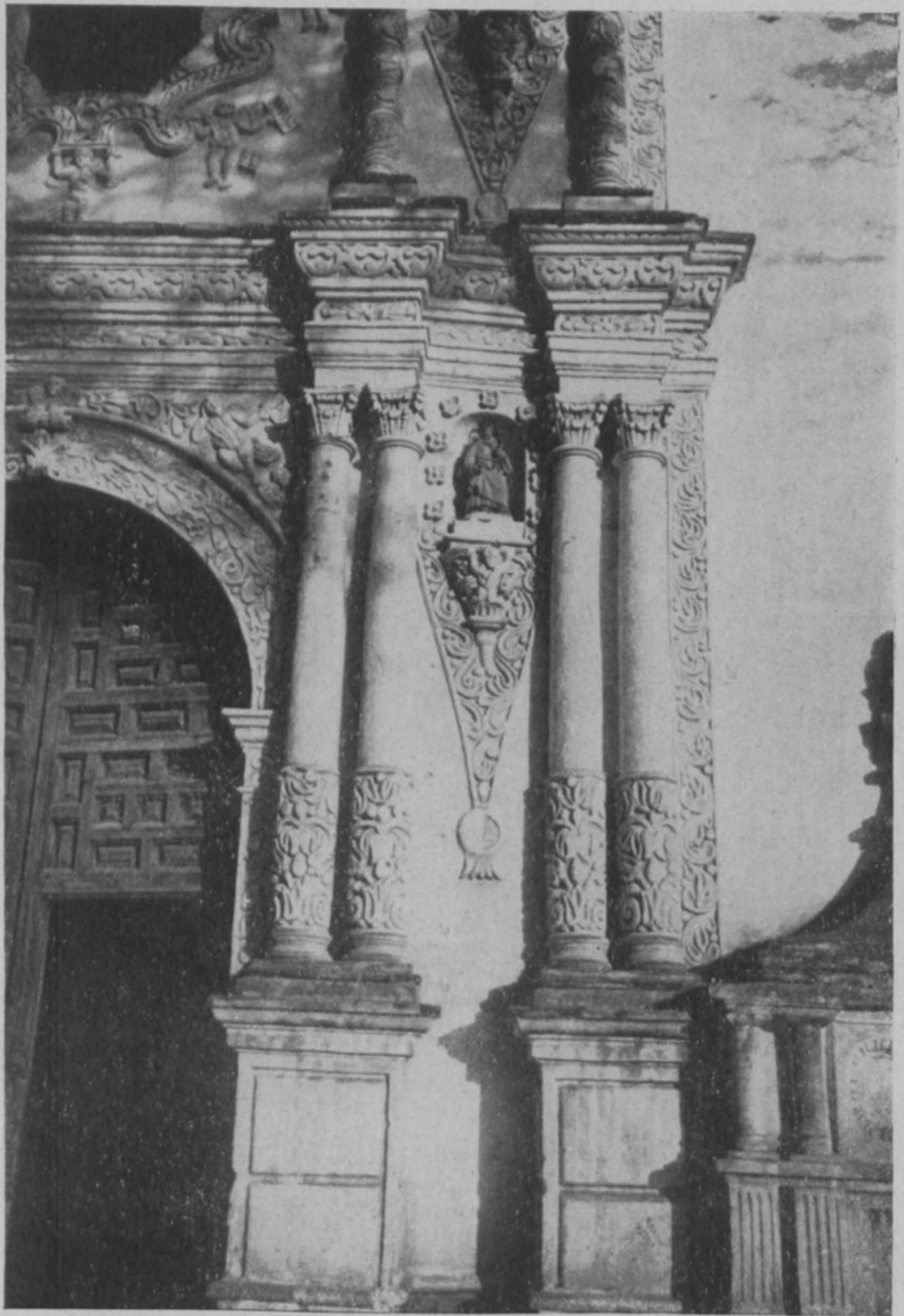

24. Detalle de la fachada del templo de Coatlinchán. 


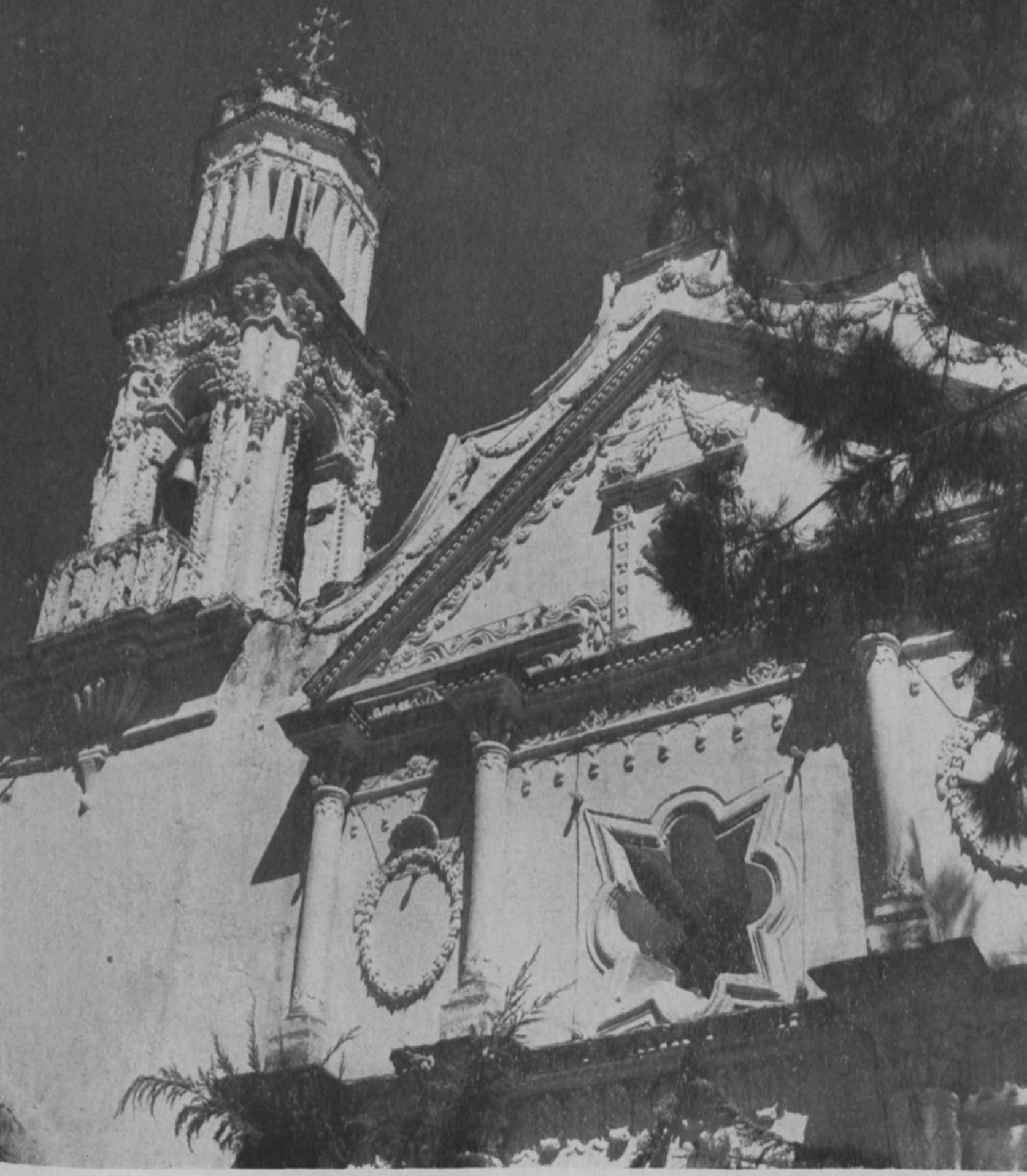

25. Fachada de la iglesia de San Sebastián. 


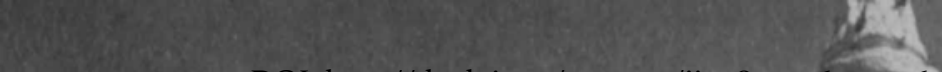

DOI: http://dx.doi.org/10.22201/iie.18703062e.1956.24.604

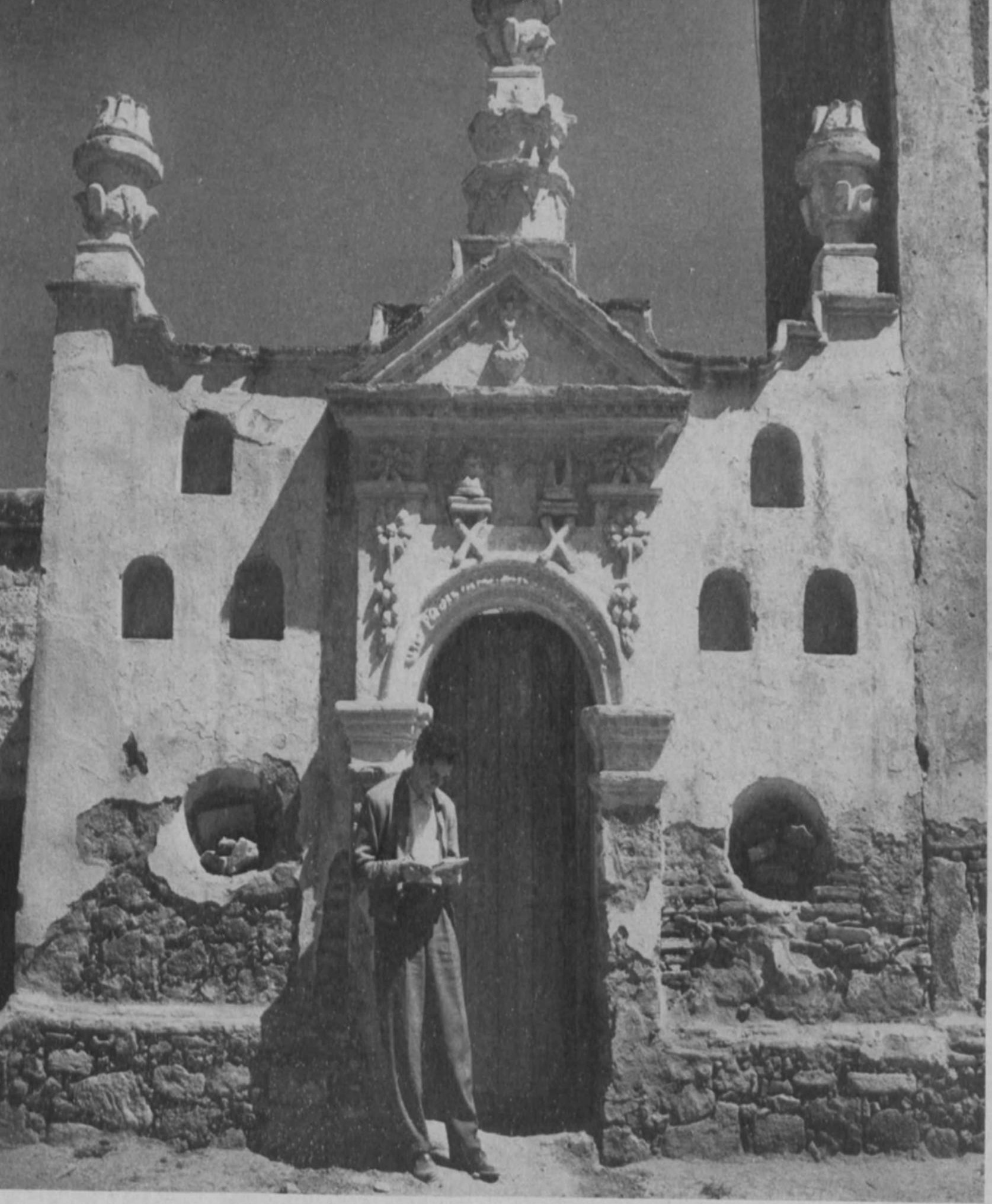

26. Fachada sepulcral de Chiconcuac. 
DOI: http://dx.doi.org/10.22201/iie.18703062e.1956.24.604

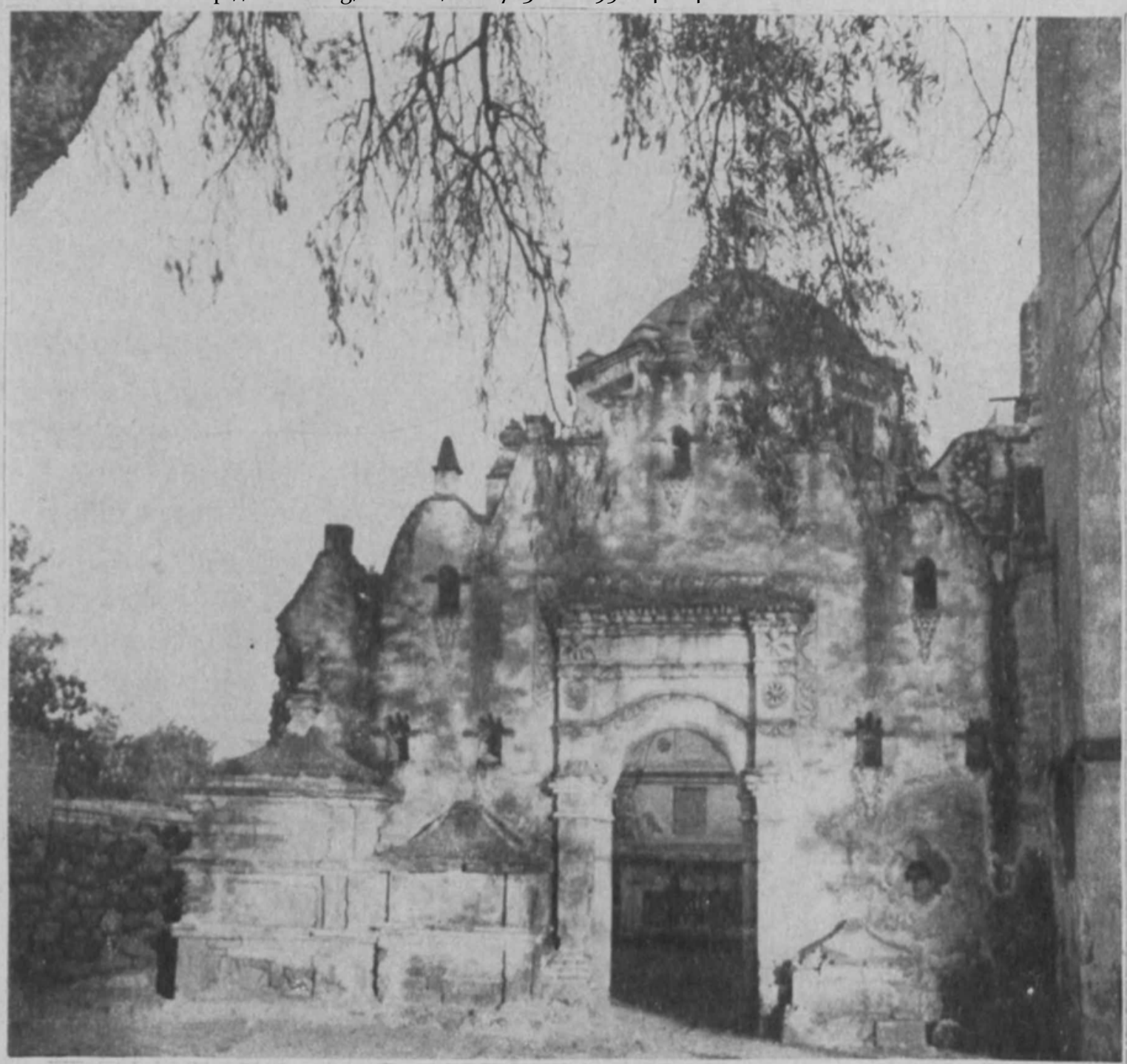

27. Fachada sepulcral de Coatlinchán. 
DOI: http://dx.doi.org/10.22201/iie.18703062e.1956.24.604 
arcadas tienen de uno a tres vanos y consecuentemente dos o cuatro columnas que soportan un macizo, formado por la reunión de las enjutas, que se presta de maravilla para ser llenado con una rica decoración en relieve. Hacia arriba este macizo termina en una cornisa que con su definida horizontalidad parece destinada a poner un hasta aquí a la ambición decorativa del artista popular; sin embargo, éste siempre la salva, la sobrepasa, para levantar encima de ella un nicho central en el que se apoyan dos roleos, a manera de pequeños arbotantes laterales, que no son sino un pretexto para mover el perfil superior de la arcada, y varios remates -algunos de ellos inspirados en la cerámica regional- dispuestos simétricamente por pares los que, en cada ocasión distintos, son un alarde de fantasía. Los ejemplares más perfectos y acabados de este tipo de arcos se hallan en los atrios de Texompan, Papalotla y Chiconcuac.

En el primer caso la arcada más interesante desde el punto de vista artístico es la que aparece, excepcionalmente, adosada a un lado de la iglesia. ¿Qué armonía en sus proporciones y en la dispasición de sus elementos! Hay una búsqueda y un logro del efecto plástico en el contraste establecido por la limpieza de los contrafuertes laterales y de los fustes de las columnas con la profusa ornamentación de las enjutas y las pilastras adosadas que limitan el arco único. Ese paso de la sobriedad al abarrocamiento, de la austera consistencia de los componentes arquitectónicamente activos a la ágil gracia de los pasivos, es de tal manera lógico que se piensa no podrían estar en otra forma. La coexistencia artística de unos y otros elementos está lograda perfectamente: entre el arco ondulante, de lejanas resonancias moriscas, y los capiteles que lo reciben con sus hojas bulbosas que si entre sus antepasados contaron con el acanto clásico, han sido transformadas por el artista popular en vigorosas plumas de águila o en carnosos pétalos de flores cactáceas; entre el nicho superior, escoltado por la atormentada helicoide de las columnas salomónicas ry la sencilla cruz que lo corona; entre la quebrada cornisa y las almenas que hunden su punta en el espacio. Por su parte el relieve que llena las enjutas, va de acuerdo con la imperceptible asimetria axial del arco; más grueso en la parte izquierda, la más chica, que en la derecha, pero en ambas se resuelve en formas fitomórficas compactas que no dejan ningún espacio libre. Apenas si en la clave, saliéndose del plano en que se desenvuelve el follaje, aparecen en el escenario de la atmósfera dos ángeles ingenuos y primitivos sosteniendo una cartela muda orlada de volutas. En las pilastras, adosadas a uno y otro lado, las relieves se ordenan en el interior de recuadros iguales variando 
en los motivos pues, las flores, estallantes de pétalos como las que en el siglo xvi esculpieron los indios en las portadas, alternan con las hojas, abiertas como manas, o con ramas de las cuales penden maduras granadas.

Este barroco espléndido se enriquece aún más, perdiendo en la finura del tratamiento, pero ganando en libertad formal, en los arcos atriales de Papalotla. Allí las arcadas son triples - los arcos laterales de medio punto, el central lobulado- y aunque los contrafuertes y aún la decoración, parecen haber sido pensados por el mismo artista de Texompan, el contraste entre los paños lisos y los que están cubiertos de relieves se ha perdido, predominando la formidable monumentalidad escultórica de estos últimos. A las columnas no les ha quedado otro remedio que sucumbir al avance del follaje, pero sucumbieron sólo a medias, hasta la mitad de su fuste, manteniendo así la dinámica visual entre los espacios plenos y vacíos de formas; aparecen además, en cada una de ellas, motivos zoomórficos: dos venados en movimiento, levantando las astas y volteando la cabeza hacia atrás, con un sintetismo que cualquier escultor contemporáneo envidiaría. Sobre el capitel un angelito hace el inútil alarde de sostener sobre sus hombros el intradós del arco, como si deveras cumpliera su papel de atlante minúsculo. En lo alto la movida hojarasca de mezcla invade los componentes del remate intentando penetrar hasta el nicho central ocupado por un santo hierático de apariencia idolátrica.

Dato importante: sobre la clave del arco medio, en la arcada del norte, está labrada una fecha, 1733, que marca el momento culminante del barroco texcocano, aquel en que, llegando a su apogeo, el estilo logró la perfecta armonía entre la arquitectura y la escultura.

La evolución artística de los arcos atriales termina con los que sirven de acceso a las iglesias de Santa María Tulantongo, San Simón y San Miguel Chiconcuac, entre otras; ellos son el testimonio de la degeneración - llamémosle así- del estilo y de la intromisión de elementos decorativos del neoclásico reciente $\mathrm{y}$ a veces de un alambicado rococó; menos exuberantes y atormentados, menos intensos y apasionados en su ejecución y en su mensaje artístico. Los arcos de medio punto o apenas lobulados, las columnas de fuste desnudo y capitel simplísimo, las enjutas vacías o con el simple toque de unas ramas o flores de un gusto cada vez más alejado del relieve indígena, hablan de un sometimiento de los artistas populares a los cánones estilísticos europeos. Sólo en los remates, infaliblemente característicos, perdura el sello texcocano 
en las formas audaces, llenadoras de espacio, $y$ en las proporciones creadas para los contempladores nativos por el artista anónimo. Allí, en lo alto, se han refugiado los carnosos pétalos, las estrellas de puntas irregulares, los extraños macetones y esa especie de sahumerios cerámicos de varios cuerpos. El nicho del centro es el último reducto de los roleos serpentinos $\mathrm{y}$ de los santos de formas idolátricas.

\section{Las bardas}

Desde las construcciones conventuales del siglo xvI se ha tratado en la arquitectura mexicana de evitar la monotonía de la línea recta en las bardas, gracias al empleo rítmico de diversos elementos de volumen apreciable. Las almenas, los garitones y los arcos fueron usados por los primeros alarifes de la Nueva España con singular maestría hermanada a la sobriedad propia de la época. En el barroco se conservó el ritmo pero se modificaron las formas, enseñoreándose la curva que alteró el perfil rectilíneo de las bardas.

Muchas son las bardas que han desaparecido o han sido transformadas a través de los años en las iglesias de los pueblos y ciudades de México, ya sea por causas accidentales, urbanísticas o simplemente por descuido e incuria. En la región de Texcoco sólo quedan dos, sin embargo, ellas son suficiente testimonio del ingenio y la inventiva populares.

La barda que circunda el atrio de la iglesia de San Andrés Chiautla no es sino la amplificación majestuosa de las molduras que, en pequeña dimensión, intervienen en los basamentos de las columnas, la media caña y el medio bocel, repetidos incesantemente para constituir una de las más hermosas bardas de la arquitectura mexicana. La gracia de sus perfiles en que se alternan lo cóncavo y lo convexo llegaría quizás al amaneramiento si no fuera por el espesor del muro que le imprime un aspecto sólido y elegante; tal parece que en esas concavidades descansa su peso la atmósfera.

La otra barda texcocana notable por su interés artístico es la que bordea el atrio de la iglesia de San Miguel Chiconcuac. Su borde redondeado está alterado por la rítmica aparición de unos basamentos de piedra; la mayoría hienden con sus aristas la superficie en que descanisan luciendo, encima, enormes macetones semejantes a aquellos que aparecen en los remates de las arcadas atriales; otros, los más cercanos a la entrada, presentan el frente, luciendo hermosas flores ornamentales que les dan importancia puesto que son el soporte de las figuras guardianas: 
niñas de ampuloso vestido y calzas a media pierna, de grandes rizos y serenos rostros, que llevan en sus brazos una maza gigante. Sin duda estas figuras extraordinarias en su popularismo, tosca y libremente trabajadas bajo un concepto escultórico que ya no puede llamarse "primitivo" puesto que se ha convertido en la máxima ambición de los artistas actuales, tuvieron como modelo a esos ángeles portadores de cirios que escoltan los altares en las iglesias del barroco "culto". Sólo que, en su interpretación, el escultor popular hizo del candelero un voluminoso garrote, de las botas angélicas unas simples calzas, del faldellín de amplios vuelos una rígida cauda ide plumas y en los rasgos del rostro, en los brazos y las manos puso ese ingenuro sello que hace amar esas sencillas obras creadas por la autenticidad emotiva y el impulso creador de los artistas del pueblo. En las arcadas laterales no son doncellas las que vigilan la puerta, sino dos leones coronados, salidos seguramente de los escudos reales de la época, que quieren ser feroces enseñando sus colmillos, pero no pueden serlo por sus ojos melancólicos, su lacia melena y sus bigotes marcados con unos cuantos garabatos esgrafiados en sus mejillas, auténticas mejillas puesto que su rostro es casi humano. Apoyando sus garras contra la arcada y recargando sus nalgas robustas en la barda permanecerán alli, desafiando a los siglos con su selvática sonrisa, como obra maestra del escultor popular de Chiconcuac.

\section{Las portadas}

La evolución artística de las portadas populares del barroco texcocano se inicia en la capilla de Santiaguito; así, en diminutivo, con ese gusto indigena por el amoroso y reverencial diminutivo, tan acorde en este caso con las proporciones del edificio.

La construcción original fué hecha en el siglo xvI, como lo atestiguan las sencillas columnas que soportan el arco renacentista y los pilares adosados que terminan hacia arriba en los típicos remates triangulares del estilo herreriano, además de algunos sellos de piedra empotrados simétricamente en la parte superior de la fachada. Seguramente, cuando Texcoco estaba rodeado por las aguas del lago, esta era la capilla del infalible barrio de Santiago. La obra se terminó en el siglo siguiente, imponiéndose sobre los elementos escurialenses las movidas formas barrocas: dos roleos insólitos a manera de enredaderas sobre la seria prestancia de los pilares $y$ algunas ramas en relieve en el interior de las enjutas; pero sobre todo, el nuevo estilo domina en la ventana que, circular y diminuta, se 
abre en un campo ornamentado al que sirve de límite un cordón franciscano. Por encima de ella y proporcional a su tamaño, un frontón se rompe por la presencia de una hornacina. Esta portada que en otras circunstancias podría pasar desapercibida, adquiere plasticidad al destacar sobre un paño liso y uniforme que termina, en lo alto, recortado por los gráciles movimientos de una cornisa que proyecta sobre el muro un finísimo toque de sombra. La capilla de Santiaguito es uno de esos ejemplos de armoniosa simplicidad arquitectónica que a menudo no se aprecia lo suficiente en las pequeñas construcciones coloniales.

San Juan Texompan es el siguiente paso en esta evolución estilística. Su fachada sigue, en estructura y composición, los mismos lineamientos generales que la de Santiaguito, sólo que es más rica y de mayores proporciones puesto que se trata de una iglesia y no de una simple capilla: el arco de medio punto en la entrada, a los lados las pilastras adosadas que rematan en pináculos piramidales, la ventana octagonal, con su marco cercenado, como en algunas otras iglesias populares, por las molduras del primer cuerpo, y un nicho pequeño en la parte más alta.

Seguramente por esta época - mediados del siglo xviI - fué levantada la portada del templo de Santa María Tulantongo que, según Betancourt, fué dedicada en 1676 , si bien la fábrica original data de la centuria anterior como lo atestiguan una cruz de atrio que yace en medio de escombros a un lado de la iglesia, aparte de que la Virgen de la Asunción que allí se venera es una deliciosa pintura del xvi, vestida con ropajes recientes pegados sobre la tabla en que fué ejecutada. Claro está que en la época del barroco no podía faltar en Texcoco una imagen que le devolviera la vista a un indio ciego con las aguas milagrosas de un manantial, de ahí que Nuestra Señora de Tulantongo tenga su "pocito", como el de la Virgen de Guadalupe o la de Ocotlán. Para Villaseñor y Sánchez, en el siglo xvir es tan milagrosa que "habiendo pasado más de doscientos años (del suceso) se advierten los colores tan vivos y naturales como si se acabaran de pintar".

La parte más bella e importante en la fachada de Santa María Tulantongo es la ventana, limpiamente cuadrada y limitada por un precioso marco de filigrana de piedra. La misma filigrana cubre el friso en que está asentada y los remates herrerianos que la escoltan, como sucede en las portadas de Santiaguito y de Texompan. El tratamiento escultórico podría confundirse con el de las obras platerescas del xvi si no fuera por las ondulaciones de los remates y el franco abarrocamiento 
del nicho culminante de la fachada; es un esculpido indígena, popular, aunque cierto es, no muy texcocano.

Pero las fachadas más hermosas del barroco popular de esta región son las de La Trinidad, iglesia situada en uno de los barrios de Texcoco, la de la capilla de San Antonio en el atrio del convento franciscano de la misma ciudad, y la de los templos de los cercanos poblados de San Simón y Chiconcuac.

La Trinidad es la fachada más pura, la más lograda como expresión plena de popularismo, es la obra de arte cumbre de esta arquitectura. En ella las peculiares proporciones de lo popular han llegado a un equilibrio perfecto; su creador o sus creadores hallaron una armonia indiscutible entre los volúmenes y los vanos, entre los espacios ornamentados $\mathrm{y}$ los lisos. Las estrías inquietas y flameantes de las pilastras del primer cuerpo se interrumpen antes de llegar al basamento dejando así un espacio libre que, además de evitar la monotonía ornamental, les resta tỏda posibilidad de esbeltez. La estética popular huye siempre de la esbeltez, tanto como de la finura amanerada en los detalies. El aspecto sólido y consistente de este primer cuerpo, sustentante de la fachada, satisface la lógica arquitectónica más elemental.

En el segundo cuerpo las pilastras laterales se adelgazan y en su interior aparecen en relieve dos cariátides que, con esa tendencia, común a todo el barroco, por hacer coexistir el mundo humano o animal con el vegetal, se resuelven hacia abajo en una pirámide invertida, cubierta de follaje, que recuerda las pilastras estípites de las iglesias cultas, la cual se hunde finalmente entre los cabellos hirsutos de unas increíbles angelitas cachetonas que, púdicamente, muestran sus senos pequeñitos. Sabedor de sus posibilidades y de sus limitaciones, el estupendo arquitecto de $\mathrm{La}$ Trinidad pensó su ventana central como un simple ochavo, aunque, eso sí, la circundó de un cordón que formando un lazo en cada esquina del vano, se destaca entre algunas estrellas. Este campo estrellado no ocupa sin embargo todo el paramento pues a dos ángeles-sirenas maravillosos se les ocurrió recargar sus cuerpos en los esbeltos tallos que nacen, a cada lado, cerca de las pilastras y los han curvado hacia el centro para rendir homenaje al Padre Eterno que, sentado serenamente con su apariencia arcaica en su nicho, se hace acompañar por San Francisco y la Virgen María colocados en sus respectivas hornacinas. El remate caprichoso está limitado como siempre por unas molduras que tratan de encontrarse en el centro con sus extremos enroscados, aunque inútilmente pues un desnudo niño indigena lo impide extendiendo sus brazos. 
Acentúan la nota popular los restos del color rojo con que originalmente estuvo pintada la fachada, igual que siglos antes, lo estaban las pirámides, los templos y los ídolos del mundo azteca.

La iglesia de San Simón es otro típico ejemplo del barroco popular texcocano, sólo que el arte que aquí aparece es menos severo en su tratamiento que el de La Trinidad. Se trata de una fachada alegre y graciosa, cubierta por completo con un relieve fitomórfico que, en contraste con la iglesia anterior, casi se antoja pensado por una mente femenina: tiene el mismo encanto que los bordados dieciochescos con los que las monjas llenaban sus ocios en los conventos coloniales. Como tratando de que los perfiles rectos que las limitan pasen desapercibidos, las pilastras que aparecen en los dos cuerpos se llenan de tallos y de flores y aún la ventana central, olvidando las aristas cortantes del ochavo, es redonda. Se nota una tímida influencia del barroco poblano en los toques talaverescos de algunos azulejos distribuidos de un modo aparentemente - solo aparentemente- arbitrario para hacer resaltar sus tonos azules y blancos sobre el color rosado que cubre toda la fachada. El suave contraste cromático -rosa predominante, azul ocasional- acentúa el sabor popular y el carácter mexicano de la decoración; mas hay otro contraste, el escultórico, entre la delicadeza de los relieves que representando al mundo de las plantas llenan todos los espacios posibles, y la concreción de las imágenes que ocupan los nichos: abajo San Pedro y San Pablo, arriba dos obispos, y en la hornacina más alta naturalmente San Simón, el patrono, todos ellos con su túnica azul y su manto encarnado, trabajado con ese "primitivismo" popular, gustoso del volumen definido y las líneas concretas, sin refinamiento alguno, con esas formas que, de tan escultóricas, casi se palpan con los ojos. Están presentes también los clásicos querubines texcocanos, con sus alas pintadas de azul añil y sus ojos somnolientos y además, el ignorado alarife de San Simón, como escapando de cualquier mirada inquisitiva, intentó en la base de la torre unas hermosas ventanas estrelladas que acaban con la seriedad del paño al herirlo con sus picos agresivos.

En el atrio del convento que en el siglo xvi construyeron los franciscanos en Texcoco, se levanta una capilla aislada, erigida en el xvin, que muestra, en todos sus detalles, un inconfundible sabor popular. La fachada principal consta de dos cuerpos y un remate. En el primero aparece la puerta escoltada por pilastras estípites pareadas. Nunca en el barroco popular se pudo entender el concepto formal de la pilastra del ultrabarroco y por ende las proporciones entre la pirámide invertida, 
el cubo central, los estrangulados cuerpos y el capitel que la constituyen son interpretados, por este, arte de una manera puramente esquemática, cuando no arbitraria. La pirámide truncada es, en la pilastra churrigueresca, el cuerpo predominante y característico, de ahí que los artistas populares lo consideren esencial y en su sintetismo escultórico reduzcan todo el soporte a una simple superposición de prismas triangulares, separados apenas por un abultamiento central que pretende recordar el cubo de las pilastras en que se inspiraron. Las enjutas de la puerta están llenas de un follaje, realizado no con ese relieve profundo y definido que aparece en otras portadas de la región, sino con un leve esgrafiado.

Al hacer la ventana del segundo cuerpo el arquitecto tuvo la pretensión de igualar a los óculos barrocos de las grandes iglesias; sólo que le falló el tino en la colocación y el espacio se le terminó, por decentrarla, al llegar a la parte inferior; pero sin inmutarse recogió un poco las ondulaciones de su ventana y las dejó descansar directamente en la cornisa. A no dudar olvidó su gracioso fracaso con la factura gozosa de esos dos ángeles pequeñitos que a uno y otro lado de la ventana llevan en sus manos símbolos pasionarios y de las columnas salomónicas, adornadas con estrias oblicuas y toscas. La fachada termina hacia arriba con un nicho y por encima de él, en una última posibilidad de elevación, una pequeña espadaña.

La portada lateral es mucho más elaborada, como si el mismo arquitecto, en un afán de desquite por la ventana fallida del frente, se hubiera esmerado hasta lo imposible en su creación. En las jambas labró un elegante almohadillado, limitado por cenefas vegetales en típico relieve texcocano, y en las enjutas esculpió, en perfecta simetría bilateral, varios ángeles -desnudos niños indígenas- que juegan, alrededor de una corona que ocupa la clave del arco, con guirnaldas que por su tratamiento semejante al "pastillaje" prehispánico, más parecen frutales que florales; en las esquinas, a dos ángeles más les rebosa el estómago por el esfuerzo que hacen al sostener la cornisa. $Y$ ya que se trata de hacer ángeles, los mayores del grupo aparecen fuera de la portada, sobre el paño del muro, caminando sobre las despeinadas cabezas de dos querubines que asoman su rostro picaresco entre sus alas. Arriba está el infaltable nicho con sus columnas salomónicas y la movida sombra de su cornisa; a sus lados se destacan dos flores de códice en relieve además de voluminosos remates cactáceos. $Y$ nuevamente aquí el arquitecto popular intentó la ventana estrellada... y le volvió a faltar el espacio necesario. Así pues, 
rodeándola de una orla ondulante y de varias flores la dejó por la paz, recargando su borde inferior en la cornisa del nicho.

$\mathrm{Y}$ henos aqui de nueva cuenta en San Miguel Chiconcuac. Ahora frente a su fachada, en la que la influencia del barroco degenerativo y el incipiente estilo neoclásico de fines de siglo compiten artísticamente por el dominio del espacio: las columnas desnudas, con sus capiteles corintios ya más cerca del acanto helénico que de las pencas mexicanas, los vacíos medallones ovalados, la insinuación de un frontón triangular en el remate y la aparición de auténticas guirnaldas con grandes flores terminales, semejantes a las que puso Tolsá en la catedral de México, preludian el advenimiento del academismo, estilo fratricida del barroco. Sin embargo nadie podría negarle a esta fachada una inefable belleza popular que nace de la todavía intensa y agitada decoración escultórica que la llena con su cálida participación artística. Es aún una fachada barroca tanto como texcocana por el arco quebrado de la entrada y su estrellada ventana, incompleta también por abajo, pero sobre todo por la presencia de esos ángeles que ya conocimos en otras iglesias en las mismas posturas y actitudes, aunque distintos en algo de su factura y expresión, un algo que obliga a gozarlos estéticamente de manera diferente, como si jamás se hubieran visto volando en su mundo de piedra y estuco portando la cruz de la fe o la balanza de la justicia o tirados de barriga para colocar una corona encima de la clave del arco. A veces el origen se impone por su evidencia: aquellos que, en el último cuerpo, se acercan al nicho central, caminando sobre las cabezas de dos querubines, salieron de la capilla de San Antonio, y esos dos, sentados en peanas especiales a los lados de la puerta, los que tienen la cabeza cubierta por una rizada peluca y soplan ferozmente sus cornetas para recibir a los fieles, esos, se inspiraron seguramente en los primitivos y estupendos ángeles trompeteros esculpidos, con técnica tan distinta por ser del siglo xvr, en la puerta plateresca de La Conchita, nombre de confianza con el que el pueblo designa a la iglesia del barrio de La Concepción en Texcoco.

Poco tiempo antes, o coincidiendo con los años en que se hizo la fachada de Chiconcuac -en las postrimerias del xviII- otras iglesias fueron concebidas por mentes definitivamente cultas de arquitectos conocedores, los cuales crearon sus obras bajo principios teóricos y prácticos perfectamente fundamentados imposibilitando, a los artistas populares, una amplia libertad de concepción. Sin embargo no se pudo evitar que éstos últimos dejaran su impronta en el tratamiento de las formas, en la ejecución manual de los motivos y aún en el ordenamiento de las proporciones 
de ciertos elementos arquitectónicos. $\mathrm{Y}$ es asi que en las iglesias de San Sebastián y en la de San Andrés Chiautla -en las que la torre, por su decoración, resta importancia a la fachada- expresión la más elevada de ese barroco afrancesado y superficial que la estructura básica de Chiconcuac deja entrever y en donde las manos sapientes de los arquitectos sí dejaron ventanas estrelladas perfectas; o en las fachadas churriguerescas de Huexotla, Coatlinchan o Coatlalpan, cuyo estupendo ultrabarroco demuestra que sus constructores sí sabían lo que era la proporción y la forma definida del estípite y las espirales de la columna salomónica, los escultores anónimos concentraron su voluntad creadora en cada detalle, tendiendo a hacer plano el relieve, carnosos los pétalos florales, robustas y estallantes las granada's, ingenuos y distorcionados los cuerpos de los ángeles, imprimiendo a estas fachadas "cultas" un inconfundible sello regional.

\section{Fachadas sepulcrales}

En algunos atrios de las iglesias texcocanas aparecen, junto al templo, unas originales fachadas cuya puerta sirve de acceso a recintos sepulcrales, más o menos grandes. Su composición general es característica: la portada destaca en el centro del muro encalado en el que unos nichos, pequeños y siempre vacíos de esculturas, cumplen una pura función ornamental. Las más notables de estas portadas se hallan en el atrio de Coatlinchan y en el de San Miguel Chiconcuac.

La primera es una sencilla estructura que adquiere importancia gracias a la elevación del paramento, horadado por los toques de claroscuro de sus nichos, que termina hacia arriba en movidos perfiles. La puerta con el sobrio barroquismo de sus líneas, no excento de cierta solemnidad, parece tratar de romper la posible angustia que pudiera uno tener al entrar al dominio de los muertos.

Más popular en sus formas es la fachada sepulcral de Chiconcuac. Realizada en el mismo estilo que la iglesia, lleva encima del arco de entrada -arco que, entre otras cosas fué construído dentro de unas proporciones sui generis que nada tienen que ver con la escala humanados pares de esqueléticas tibias cruzadas que soportan una tiara pontificia y una mitra episcopal recordando que, para todos, aun para los Papas y los obispos, es válida la sentencia fatal del pulvis eris. Pero esta alusión a la muerte, interpretada por el arte popular, no puede ser tenebrosa ni patética. ; Cómo ha de serlo si junto al símbolo funerario aparecen 
flores de cempoalxóchitl y guirnaldas, en formas plenas de lirismo y sensualidad escultórica; cómo si sobre el frontón, ornado con desmesurados dientes de ascendencia clásica, se levanta un remate enorme de varios cuerpos culminado por el macetón texcocano, con tal desproporción con respecto a la portada que parece un monumento al goce creativo del artista al esculpir cada uno de los volúmenes, casi palpitantes, de su obra! Para él, este elemento era el motivo principal y no el simple remate de la deliciosa portada.

El barroco popular de Texcoco, como todos los estilos, tuvo pues un perceptible desenvolvimiento, desde su nacimiento hasta su muerte. Para seguir su trayectoria artística hemos recurrido aquí al estudio, no de todos los monumentos existentes, pero sí de los más significativos.

La tímida aparición del estilo en Santiaguito, la afirmación de sus características definitivas en Texompa, su posterior esplendor en Tulantongo, Texcoco, San Simón y Chiconcuac, su culturización en las iglesias de Huexotla y Coatlinchan y su agonizante pero siempre espléndida presencia en los templos de Chiautla y San Sebastián, patentizan la identificación espiritual que el pueblo encontró con las formas barrocas en la época más brillante del arte de la Nueva España. 